\title{
Participación del polimorfonuclear neutrófilo en la respuesta inmune contra Paracoccidioides brasiliensis
}

\author{
Angel González ${ }^{1,2}$, Luz E. Cano ${ }^{2,3}$ \\ ${ }^{1}$ Corporación Ciencias Básicas Biológicas, Universidad de Antioquia, Medellín, Colombia. \\ ${ }^{2}$ Corporación para Investigaciones Biológicas, Medellín, Colombia. \\ ${ }^{3}$ Escuela de Bacteriología y Laboratorio Clínico, Universidad de Antioquia, Medellín, Colombia.
}

La paracoccidioidomicosis, micosis profunda de gran importancia en Latinoamérica, se caracteriza por presentar una respuesta inflamatoria aguda en el pulmón, órgano blanco del proceso infeccioso. En las etapas iniciales, esta respuesta se caracteriza principalmente por un infiltrado de polimorfonucleares neutrófilos (PMN), los que, de acuerdo con estudios histopatológicos y de lavados broncoalveolares, representan más del $85 \%$ de las células allí presentes. Las evidencias presentadas en esta revisión sugieren que el PMN participa activamente en la respuesta inflamatoria aguda inducida por Paracoccidioides brasiliensis, como lo demuestra la inhibición de su crecimiento después de su interacción con tales PMN. Igualmente, se conoce que algunas etapas del mecanismo fungicida exhibido por esta célula fagocítica están mediadas por los reactivos intermediarios del oxígeno, así como también por el efecto activador de algunas citocinas como IFN $\gamma$, GM-CSF e IL-1 $\beta$. En efecto, fracciones o componentes del hongo inducen la migración al sitio inflamatorio y la activación de los PMN, evidenciada por el aumento en los productos del estallido respiratorio.

Palabras clave: polimorfonuclear neutrófilo, Paracoccidioides brasiliensis, paracoccidioidomicosis, estallido respiratorio, respuesta inflamatoria.

\section{Polymorphonuclear neutrophil participation in immune response to Paraccocidioides brasiliensis}

Paracoccidioidomycosis, a systemic mycosis of great importance in Latin America, is histologically characterized by an acute inflammatory response in the lung target organ. During the early stages of infection, tissue response is mainly characterized by the presence of polymorphonuclear neutrophils (PMN) which represent over $85 \%$ of all cells (demonstrated by histopathology and bronchoalveolar lavage). Evidence is presented herein that PMNs actively participate during the acute inflammatory response induced by Paracoccidioides brasiliensis. This is shown by growth inhibition following the interaction of the fungus with these phagocytic cells. Certain of the killing mechanisms exhibited by this phagocytic cell are mediated by the reactive oxygen intermediates, as well as by the activating mechanisms exerted by certain cytokines (IFN- $\gamma, \mathrm{GM}-\mathrm{CSF}$ and IL-1 $\beta$ ). Furthermore, fungal fractions or components are capable of inducing both activation of PMN and migration to the inflammatory site as revealed by the increase of the products resulting from the respiratory burst.

Key words: polymorphonuclear neutrophil, Paracoccidioides brasiliensis, paracoccidioidomycosis, oxidative burst, inflammatory responses.

Correspondencia:

A. Gónzalez, Corporación para Investigaciones Biológicas, Carrera 72 A \# 78 B-141, Medellín, Colombia. Tel.: (04) 4410855; fax: (04) 441-5514 angelgo39@hotmail.com

Recibido: 09/03/01; aceptado:25/05/01
La paracoccidioidomicosis (PCM) es una micosis sistémica de gran importancia en Latinoamérica, principalmente en Brazil, Colombia y Venezuela (1). Esta micosis se produce por la inhalación de los propágulos infectantes (conidias) del hongo dimórfico Paracoccidioides brasiliensis que, al 
alcanzar el pulmón, órgano blanco, inician allí un proceso de transformación a levadura, el cual lleva al desarrollo de la micosis (1).

Estudios en modelos experimentales han mostrado que la inoculación intranasal de conidias de $P$. brasiliensis en los estadios tempranos de la infección origina una respuesta inflamatoria aguda pulmonar, la cual está representada, primordialmente $(>85 \%)$, por un infiltrado de polimorfonucleares neutrófilos (PMN), como lo evidencian la histopatología del tejido pulmonar (2) y el estudio del fluido de lavados broncoalevolares (LBA) $(3,4)$.

Las células del sistema fagocítico constituyen la primera línea de defensa del sistema efector de la respuesta inmune natural y adaptativa. Por ello, Kashino y colaboradores (5), al estudiar los resultados del bloqueo de macrófagos $(\mathrm{M} \phi)$, sugirieron que éstos jugaban un papel fundamental en la resistencia a P. brasiliensis. Adicionalmente, González y colaboradores (6) demostraron in vitro el papel del $\mathrm{M} \phi$ y encontraron que al activar $\mathrm{M} \phi$ murinos con interferón gamma (IFN $\gamma$ ), su capacidad fungicida contra P. brasiliensis no sólo se hacía más aparente sino que se cumplía por mediación del óxido nítrico (NO).

EI PMN, una importante célula fagocítica que media la respuesta inflamatoria en las fases tempranas de la infección, contiene en su citoplasma dos tipos de gránulos: los específicos, que contienen enzimas degradativas como lisozimas, colagenasas y elastasas, y los gránulos azurófilos, los cuales están compuestos de lisozima (7).

El papel de los PMN en esta micosis ha sido estudiado tanto in vivo como in vitro. Así, el desarrollo de modelos experimentales en ratones susceptibles (B10.A) y resistentes (A/Sn) permitió demostrar que la infección por $P$. brasiliensis inducía en ambas cepas de ratones un infiltrado inflamatorio caracterizado por presencia marcada de PMN. Sin embargo, cuando los animales eran privados de tales células mediante la administración de anticuerpos monoclonales RB6-8C5 antigranulocitos, se presentaba un cambio diferencial en la respuesta inflamatoria, pero sin modificación de la carga micótica (8).
Estudios in vitro han mostrado que los PMN resultantes de una reacción inflamatoria tienen una mayor actividad antifúngica que aquéllos provenientes de sangre periférica. Además, tal actividad está relacionada con su capacidad de producir reactivos intermediarios de oxígeno como productos del estallido respiratorio (9).

Hasta el momento, no se conoce exactamente cuál es el papel que juega el PMN en la respuesta inflamatoria temprana inducida por $P$. brasiliensis. Aunque los estudios enunciados anteriormente sugieren que esta célula fagocítica participa tanto in vivo como in vitro en la respuesta inflamatoria y que, gracias a los productos del estallido respiratorio, tiene también una moderada actividad fungicida contra $P$. brasiliensis, los mecanismos exactos por los cuales ejerce su actividad antifúngica no han sido aún completamente esclarecidos.

En esta revisión se dan a conocer evidencias sobre la participación del PMN en la respuesta inmune contra $P$. brasiliensis y se analizan algunos de los mecanismos antifúngicos mediados por ciertos componentes del sistema inmune.

\section{Presencia del PMN durante la respuesta inflamatoria inducida por $P$. brasiliensis}

Las células fagocíticas de sangre periférica (monocitos y PMN) pueden responder a estímulos quimiotácticos que les permiten migrar de la sangre a los sitios de infección. Cuando $P$. brasiliensis ingresa al hospedero, debe interactuar con muchas células efectoras; sin embargo, es capaz de resistir los mecanismos microbicidas. Como se analiza a continuación, la interacción de las células efectoras, principalmente del PMN con la conidia, la estructura infectante del hongo y con la levadura ya han sido estudiadas (9) (cuadro 1).

En los modelos murinos, los estudios histopatológicos secuenciales han revelado la cinética de la respuesta inflamatoria, la cual muestra 3 estadios: 1) neutrofílico o monocito-neutrofílico, en el cual se observan histiocitos y PMN que son testigos de un proceso inflamatorio temprano; 2) granuloma mixto, en el cual se observan granulomas epitelioides pero aun con un componente importante de PMN y 3) granulomatoso y fibrótico- 
Cuadro 1. Presencia del PMN en el tejido inflamatorio en animales infectados con $P$. brasiliensis.

\begin{tabular}{|c|c|c|c|c|}
\hline \multirow[t]{2}{*}{ Modelo animal } & \multicolumn{4}{|c|}{ Ruta de inoculación e inóculo utilizado } \\
\hline & in $C, L \circ F$ & ip ${ }^{\mathrm{L}}$ & $s c^{L}$ & Referencias \\
\hline Ratones BALB/c salvajes $\left(\mathrm{nu}^{+/+}\right)$ & Abundantes & $\mathrm{SD}$ & SD & $2,3,4,15$ \\
\hline Ratones BALB/c eutímicos $\left(\mathrm{nu}^{+/ /}\right)$ & SD & Abundantes & SD & 8,14 \\
\hline Ratones BALB/c atímicos $\left(\mathrm{nu}^{-1}\right)$ & SD & Abundantes & SD & 8,14 \\
\hline Ratones B10 A & SD & Escasos & Abundantes & 8,13 \\
\hline Ratones A/Sn & SD & Abundantes & Moderados & 8,13 \\
\hline Ratas & SD & Abundantes & SD & 11 \\
\hline
\end{tabular}

in: intranasal; ip: intraperitoneal; sc: subcutánea

$\mathrm{C}$ : conidia; L: levadura; F: fragmentos de pared de levadura $\mathrm{SD}$ : $\sin$ datos

fibroblástico, caracterizado por la presencia de abundantes células gigantes multinucleadas, histiocitos, $M \phi$ y tejido conjuntivo fibroso $(2,3,10,11)$. También se ha observado la presencia de PMN en granulomas humanos (12).

En ratones $B A L B / C$ inoculados intranasalmente con conidias de $P$. brasiliensis, se demostró que entre la segunda y la cuarta semana postinfección ocurría un incremento significativo en la celularidad del LBA con predominio de PMN, células que representan más del $85 \%$ del total $(3,4)$. Bedoya y colaboradores (13) observaron que en su modelo experimental en ratones machos $\mathrm{BALB} / \mathrm{c}$, inoculados con levaduras o conidias viables del hongo, la infección inducía un infiltrado de células inflamatorias con predominio de PMN. Igualmente, en otro modelo en el que se utilizaron fragmentos de pared celular de levadura, se encontró una intensa respuesta inflamatoria compuesta principalmente por PMN (2).

En otro modelo en el que se utilizaron ratones BALB/c eutímicos $\left(\mathrm{nu}^{+/}\right)$y atímicos $\left(\mathrm{nu}^{-/}\right)$, se observó que, en ambos grupos, los PMN y los $\mathrm{M} \phi$ constituían las células predominantes; además, la destrucción del hongo y la presencia de partículas del hongo estuvieron asociadas con la acumulación local de estas células fagocíticas. Por otro lado, en ambos grupos de animales se demostró que desde la primera semana postinfección había ya evidencias de destrucción del hongo y de un cierto control sobre su proliferación (14).

Por otro lado, al comparar la evolución de las lesiones desarrolladas en el omentum de ratones resistentes ( $\mathrm{A} / \mathrm{Sn}$ ) inoculados intraperitonealmente con levaduras de $P$. brasiliensis, se observó que estos animales presentaban lesiones con abundantes PMN y que en ellas existían pocas levaduras, ya que la destrucción del hongo había sido masiva; por el contrario, en los ratones susceptibles (B.10A) se observaban lesiones con un gran número de levaduras multigemantes en plena actividad y sin evidencia de destrucción. Esto indicaba la influencia del patrón genético del hospedero sobre el tipo de lesión desarrollada (15). Al inocular estas mismas cepas de ratones por vía subcutánea, se encontró cómo en las etapas tempranas de la infección y en ambas cepas, el infiltrado inflamatorio se caracterizaba por una gran abundancia de PMN y que ésta, a su vez, era más notoria en los ratones B10.A (8). Adicionalmente, si antes de la infección se suprimían los PMN con el anticuerpo monoclonal RB6-8C5, la cinética del proceso inflamatorio en ambas cepas de ratones cambiaba diferencialmente, pero sin lograr modificar la carga micótica de la lesión. En efecto, en los ratones de ambas cepas privadas (depleted) de PMN, la respuesta de hipersensibilidad de tipo tardío (delayed type hypersensibility, DTH) disminuyó mientras que el título de anticuerpos contra la gp43 aumentó (8). Estos resultados sugieren que, de alguna forma, los PMN podrían participar en los varios mecanismos regulatodores de la respuesta inmune.

Todos los estudios anteriores han demostrado la presencia del PMN como componente de la respuesta inflamatoria desarrollada durante el proceso infeccioso inducido por $P$. brasiliensis o 
por algunos de sus componentes, lo cual sugiere que esta célula fagocítica participa activamente en los procesos de la respuesta inmune, si bien su función o los mecanismos involucrados no han sido aún claramente definidos.

\section{Interacción de fracciones o componentes de $P$. brasiliensis con el PMN}

Varios investigadores han estudiado el papel que juegan diferentes componentes de $P$. brasiliensis en la respuesta inflamatoria y en la activación celular (2,16-20). Así, la fracción F1 que presenta una mayor proporción de polisacárido $\beta$-glucán de la pared celular insoluble en álcalis y extractos lipídicos, ha mostrado ser capaz de inducir una respuesta inflamatoria, así como la migración celular, con un mayor componente de PMN (16, 17). Igualmente, la inoculación intraperitoneal de polisacáridos de la pared celular y de extractos lipídicos en ratas inducen la migración de células inflamatorias, principalmente PMN, en las primeras 4 a 24 horas postinoculación (20).

Adicionalmente, los trabajos realizados con la fracción F1 obtenida de aislamientos del hongo caracterizados por diferentes grados de virulencia, mostraron que la fracción proveniente de los aislamientos virulentos era capaz de estimular un mayor aumento en la quimioluminiscencia de los PMN, en comparación con la misma fracción procedente de aislamientos de baja virulencia. Esto indica que tal fracción es capaz de inducir un aumento en la producción de reactivos intermediarios del oxígeno (17), demostrados por quimioluminiscencia, técnica por la cual estos radicales, al unirse con el luminol, emiten fotones que son medidos en un contador de centelleo (21). La activación de los PMN ocurre bajo ciertas condiciones, por ejemplo, durante la fagocitosis o en cultivos in vitro en presencia de ciertas citocinas como (IFN $\gamma$ ). A su vez, la activación puede modular la capacidad metabólica de esta célula, así como también incrementar los productos del estallido respiratorio (21).

Por otra parte, los polisacáridos de la pared celular del hongo, los cuales son insolubles en álcalis, también son capaces de inducir un aumento en la respuesta del estallido respiratorio en los PMN, la cual se acompaña de su migración (16).
Además, la estructura o la composición de los constituyentes de la pared celular pueden diferir en su capacidad para estimular o inducir la respuesta inflamatoria, así como en la activación celular, especialmente en los PMN (17).

Recientemente, Cock y colaboradores (2) observaron que fragmentos de levaduras de $P$. brasiliensis, inoculados intranasalmente en ratones $\mathrm{BALB} / \mathrm{c}$, inducían una respuesta inflamatoria con predominio de PMN solamente durante la primera semana postinoculación. Por el contrario, los animales inoculados por la misma vía con conidias viables del hongo, aunque también daban lugar a una respuesta inflamatoria marcada con predominio de PMN, diferían de los animales inoculados con fragmentos de levadura, ya que la respuesta de PMN persistía durante las 16 semanas del estudio.

Estos hallazgos indican que diferentes fracciones o componentes del hongo inducen una respuesta inflamatoria caracterizada por una importante participación del PMN y que, a su vez, ésta puede correlacionarse con la virulencia de los aislamientos de los cuales provienen las diferentes fracciones. Estos hallazgos podrían contribuir a la comprensión de la forma en que se genera la respuesta inflamatoria y cómo se mantiene en actividad el proceso infeccioso en la PCM $(2,16-20)$.

\section{Activación del PMN por el sistema del complemento y su actividad frente a P. brasiliensis}

La activación diferencial de las dos vías del sistema del complemento (C') se ha demostrado en muchos microorganismos, ya que estas vías son factores que repercuten en la virulencia o en la patogenicidad de las varias cepas de microorganismos estudiados (17). Por ejemplo, se ha demostrado que la utilización de la fracción $\mathrm{F} 1$ de $P$. brasiliensis proveniente tanto de cepas virulentas como de baja virulencia, al ser adicionada a sueros normales de ratas, resultaba en diferentes grados de inhibición de las vías clásica y alterna del complemento. Además, la absorción previa del suero con la fracción F1 suprimía completamente la activación de la vía clásica. Por otra parte, si se usaba únicamente zymosan para el proceso de absorción, el resultado era el mismo, 
lo cual sugiere que los anticuerpos naturales o inespecíficos son los responsables de la activación de la vía clásica (17).

En ratas, el uso de polisacáridos de la pared celular de $P$. brasiliensis insolubles en álcalis y preincubados con suero normal resulta en una respuesta migratoria de $\mathrm{PMN}$, proceso que puede abolirse inactivando el suero por calor, lo que indica compromiso de componentes termolábiles, tipo complemento (16).

Estos resultados sugieren, por tanto, que el sistema del C' tiene importancia en la respuesta inflamatoria y en el reclutamiento de los PMN observados en la PCM experimental o en aquélla inducida por ciertos componentes del hongo.

\section{PMN: actividad fungicida/fungistática contra $P$. brasiliensis}

Por medio de cocultivos in vitro, se ha investigado la actividad fungicida o fungistática de los PMN humanos y murinos. La magnitud del efecto antifúngico de estas células varía de acuerdo con el aislamiento del hongo, por lo cual se observa un patrón de cepas resistentes y otro de cepas susceptibles (22-24) (cuadro 2).
Así, Kurita y colaboradores (22) utilizaron PMN humanos y observaron que tales células no eran capaces de destruir las levaduras de $P$. brasiliensis. Sin embargo, en cultivos prolongados (72 horas), se anotó un efecto fungistático. Además, durante las primeras 2 horas de cocultivo, la activación de los PMN con IFN $\gamma$ aumentaba la capacidad antifúngica sobre las cepas susceptibles, la cual se incrementaba después de las 24 horas. Por otra parte, en cepas consideradas resistentes, los PMN activados con esta citocina mostraban un efecto fungistático (22).

Por otra parte, al activar PMN humanos con factor estimulante de colonias granulocito-macrófago (GM-CSF) e interleucina-1 (IL-1), se aumentaba su actividad antifúngica frente a cepas susceptibles de P. brasiliensis, de acuerdo con la disminución del número de las unidades formadoras de colonia (UFC). Al combinar estas citocinas (GM-CSF + IFN $\gamma$ ), se observaba un efecto sinérgico sobre su actividad antifúngica (23). Los mismos investigadores (22) utilizaron lisados de PMN sin lograr demostrar efectos similares, sugiriendo, entonces, que era necesario contar

Cuadro 2. Efecto antifúngico de los PMN y de las citocinas en cocultivos (24 horas) de acuerdo con la reducción de UFC de $P$. brasiliensis *.

\begin{tabular}{|c|c|c|c|c|}
\hline \multirow[t]{3}{*}{ PMN } & \multirow[t]{3}{*}{ Citocina } & \multicolumn{2}{|c|}{ Cepa de $P$. brasiliensis } & \multirow{3}{*}{ Referencia } \\
\hline & & \multicolumn{2}{|c|}{ (\% de reducción de UFC) } & \\
\hline & & $\begin{array}{r}\text { Resistente } \\
\text { (Tatu-Aoki) }\end{array}$ & $\begin{array}{c}\text { Susceptible } \\
\text { (Bt-4) }\end{array}$ & \\
\hline $\operatorname{Sin} \mathrm{PMN}$ & Ninguna & 0 & 0 & 22,23 \\
\hline \multirow{10}{*}{$\begin{array}{l}\text { Con PMN } \\
\text { humano }\end{array}$} & Ninguna & $26,3-35,3$ & $67,7-84,0$ & 22,23 \\
\hline & IFN $\gamma$ & $46,2-50,0$ & $89,0-95,1$ & 22,23 \\
\hline & GM - CSF & 57,3 & 97,7 & 23 \\
\hline & $\mathrm{IL}-1 \beta$ & 31,7 & 92,9 & 23 \\
\hline & G-CSF & 29,2 & 83,3 & 23 \\
\hline & $\mathrm{IFN} \gamma+\mathrm{GM}-\mathrm{CSF}$ & 63,4 & 98,5 & 23 \\
\hline & $\mathrm{IFN} \gamma+\mathrm{IL}-1 \beta$ & 53,6 & 98,1 & 23 \\
\hline & $\mathrm{GM}-\mathrm{CSF}+\mathrm{IL}-1 \beta$ & 58,5 & 97,4 & 23 \\
\hline & TNF $\alpha$ & 29,3 & 68,5 & 22 \\
\hline & IL-8 & 23,6 & 66,1 & 22 \\
\hline \multirow{3}{*}{$\begin{array}{l}\text { Con PMN } \\
\text { murino }\end{array}$} & Ninguna & 36,1 & 78,4 & 24 \\
\hline & IFN $\gamma$ & 74,2 & 90,3 & 24 \\
\hline & TNF $\alpha$ & 33,7 & 0 & 24 \\
\hline
\end{tabular}

* Comparado con el control sin PMN 
con un PMN viable para lograr el efecto antifúngico (cuadro 2).

Recientemente, se demostró morfológicamente el efecto antifúngico de PMN humanos contra $P$. brasiliensis por medio de microscopía electrónica de barrido (22). Cuando las células en fase de levadura eran cocultivadas con PMN humanos durante 24 horas, la superficie celular de la levadura revelaba daños estructurales y, adicionalmente, su multiplicación, medida por UFC, se inhibía considerablemente (22) (figura1).

Al utilizar PMN peritoneales de ratón (24), se encontró que estas células fagocíticas ejercían actividad fungicida contra cepas de susceptibilidad intermedia, la cual se incrementaba al activar tales células con IFN $\gamma$, lo cual demostraba que el PMN murino ejercía una actividad fungicida más potente que el humano. Por otro lado, McEwen y colaboradores (21) estudiaron la actividad antifúngica de $\mathrm{PMN}$ obtenidos de sangre periférica de ratones y PMN estimulados al inocular intraperitonealmente tioglicolato o antígeno de $P$. brasiliensis en ratones previamente sensibilizados con el hongo, así como en animales control. Se encontró que los PMN sensibilizados y estimulados con antígenos del hongo eran capaces de disminuir notablemente las unidades formadoras de colonia (UFC) en aproximadamente un $40 \%$, revelando así que la sensibilización del hospedero con $P$. brasiliensis resulta en activación del PMN, célula que es ya capaz de ejercer un efecto antifúngico significativo. Brummer y colaboradores (25) y Morrison y colaboradores (26) observaron resultados similares al utilizar PMN de ratones previamente sensibilizados (o estimulados) con un agente inflamatorio y retados intraperitonealmente con antígeno de Blastomyces dermatitidis. Estos PMN presentaban ya un mayor efecto fungicida contra este hongo dimórfico. En otro modelo, Newman y colaboradores (27) encontraron que PMN humanos presentaban una

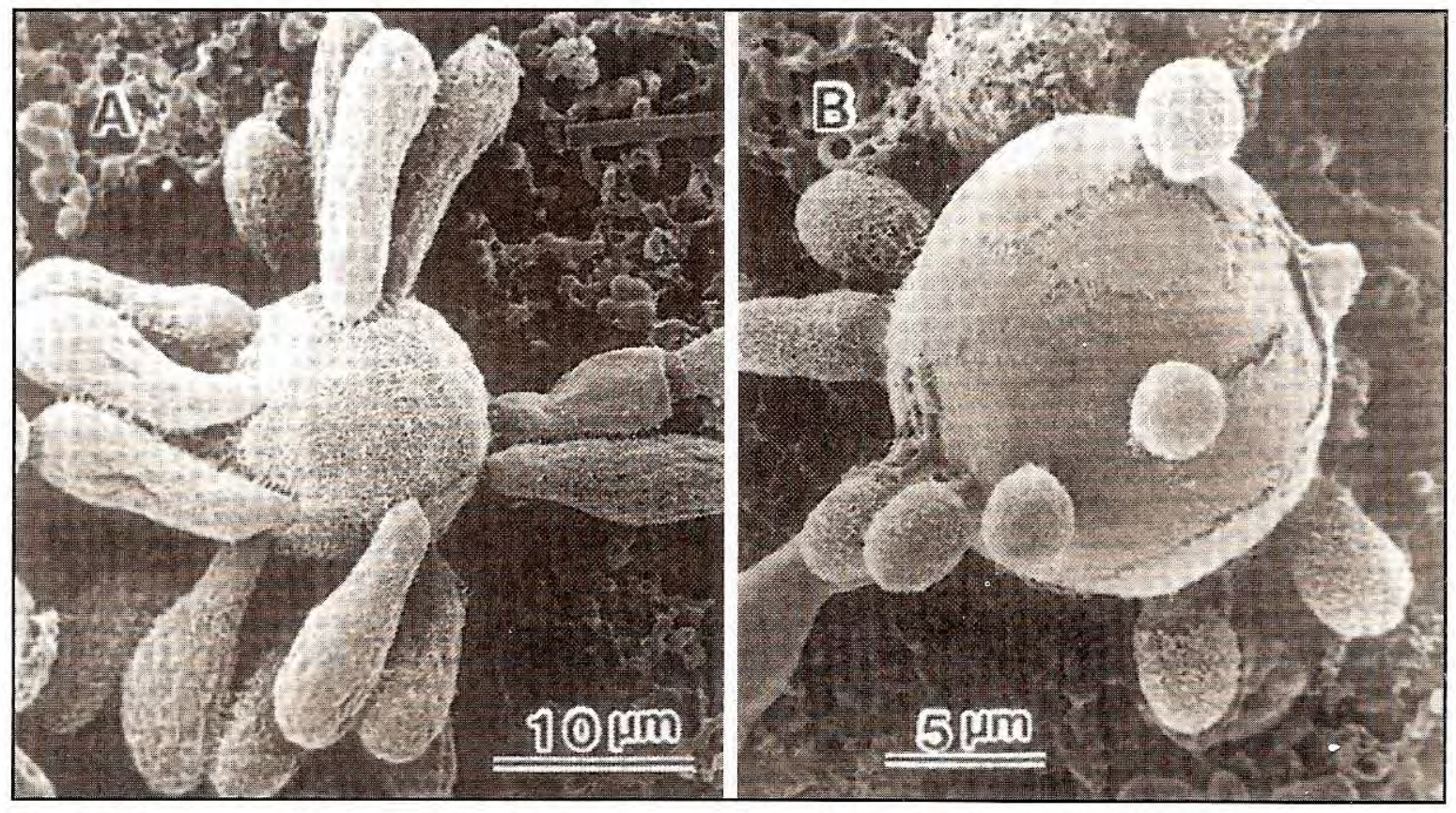

Figura 1. Microscopia electrónica de barrido de un aislamiento de Paracoccidioides brasiliensis después de 24 horas de cultivo: (A) sin PMN y (B) con PMN, en donde se observa un daño estructural aparente en la superficie de la levadura, con reducción notoria de su crecimiento (reproducción con permiso de Kurita N, et al. Med Mycol 1999;37:261-7). 
potente actividad fungistática contra levaduras del hongo dimórfico Histoplasma capsulatum, demostrado por una inhibición en el crecimiento (UFC) de las levaduras y cuantificado por su incapacidad para incorporar leucina tritiada $\left({ }^{3} \mathrm{H}\right.$ L). Igualmente, Brummer y colaboradores (28) y Kurita y colaboradores (29) lograron demostrar que los PMN humanos ejercen efectos de tipo fungicida y fungistático contra $H$. capsulatum.

Los datos anteriores demuestran que el PMN juega un importante papel en la respuesta inmune contra una gran variedad de hongos, entre ellos, $P$. brasiliensis, gracias a mecanismos fungicidas y fungistáticos.

\section{Efecto de las citocinas en la actividad antifúngica de los PMN contra $P$. brasiliensis}

En estudios previos, Kurita y colaboradores (22) habían observado que PMN humanos de sangre periférica exhibían un efecto fungistático sobre levaduras de $P$. brasiliensis, siempre y cuando fueran activados con IFN $\gamma$. Este efecto dependía, a su vez, de la cepa del hongo utilizada. En estos experimentos, se utilizó TNF $\alpha$ e IL-8, citocinas que no tuvieron efecto alguno sobre la actividad antifúngica de esta clase de PMN humanos (cuadro 2). Por el contrario, otros investigadores (30), al utilizar un modelo con Candida sp., demostraron que el TNF $\alpha$ y los receptores de TNF $\alpha$ - éstos últimos presentes en los neutrófilos - juegan un papel importante en la activación de tales fagocitos.

EI IFN $\gamma$, citocina de gran importancia en la modulación de la respuesta inmune, tiene un efecto protector en la paracoccidioidomicosis, como fuera demostrado por Cano y colaboradores (31). En un modelo con el hongo dimórfico $B$. dermatitidis (32), se demostró que PMN de sangre periférica podían ser activados in vivo con IFN $\gamma$, aumentando así en forma dosis-dependiente su capacidad fungicida. El bloqueo del IFN $\gamma$ con antisuero antiIFN $\gamma$ hiperinmune de conejo resultaba en la inhibición de la actividad antifúngica, tanto in vivo como in vitro $(33,34)$.

Al estudiar el papel de otras citocinas, Kurita y colaboradores (23) demostraron que el GM-CSF y la IL-1 $\beta$ aumentaban la actividad antifúngica de PMN frente a aislamientos de $P$. brasiliensis catalogados como de resistencia intermedia a la fagocitosis. El GM-CSF aumentaba el efecto fungistático sobre aislamientos de $P$. brasiliensis resistentes al efecto antifúngico de $\mathrm{PMN}$, mientras que el G-CSF no ejercía ningún efecto sobre la activación del PMN y, por consiguiente, tampoco sobre el hongo (cuadro 2).

Algunas combinaciones de citocinas, tales como IFN $\gamma$ con GM-CSF o IL-1 $\beta$, mostraban un efecto sinérgico sobre el aumento de la actividad antifúngica de los PMN. Por el contrario, cuando se utilizaba la combinación de GM-CSF con IL-1 $\beta$ no se observaba ningún aumento en la capacidad antifúngica de los PMN (23) (cuadro 2).

Estos datos sugieren, entonces, que los PMN activados con IFN $\gamma$, GM-CSF o IL-1 $\beta$ jugarían un papel importante en la defensa del hospedero contra la infección por $P$. brasiliensis, gracias al aumento de su actividad antifúngica.

\section{Efecto del metabolismo oxidativo de los PMN contra $P$. brasiliensis}

Uno de los principales mecanismos microbicidas de los PMN es el mediado por los productos del estallido respiratorio, entre los cuales se encuentran el peróxido de hidrógeno $\left(\mathrm{H}_{2} \mathrm{O}_{2}\right)$, los radicales hidroxilo $(\mathrm{OH})$ y los singletes de óxigeno $\left(\mathrm{O}_{2}{ }^{-}\right)$, así como la mieloperoxidasa.

McEwen y colaboradores (21) observaron una correlación en la muerte de $P$. brasiliensis por PMN provenientes de ratones sensibilizados con el hongo y su capacidad para producir un aumento en los reactivos intermediarios del oxígeno provenientes del estallido respiratorio, medido por un aumento en la quimioluminiscencia.

Por medio de la técnica anterior, Meloni-Bruneri y colaboradores (35) estudiaron también el papel de los PMN frente $P$. brasiliensis a través de la inducción de los productos del estallido respiratorio. Estos investigadores obtuvieron PMN de pequeñas bolsas de aire (airpouch) previamente inoculadas con levaduras de $P$. brasiliensis y aplicadas intradérmicamente en ratones susceptibles (B10A) y resistentes $(A / J)$. El metabolismo oxidativo de estos PMN se evaluó 
también por la emisión de quimioluminiscencia, aumentada por el luminol y la lucigenina. Los PMN extraidos de estos animales infectados se estimularon con ésteres de forbol meristato acetato (PMA) o P. brasiliensis muerto (inactivo). Se encontró que 24 horas después de la infección, ambas cepas de ratones (susceptibles y resistentes) mostraban una respuesta similar, la que se mantenía durante los primeros 15 días postinfección. Por el contrario, los PMN de ratones resistentes y estimulados con $P$. brasiliensis no viable mostraron un marcado aumento en la quimioluminiscencia, la que, a su vez, fue inhibida por la adición de catalasa (la cual descompone el $\mathrm{H}_{2} \mathrm{O}_{2}$ en $\mathrm{H}_{2} \mathrm{O}+\mathrm{O}_{2}$ ). Por otra parte, se observó una baja quimioluminiscencia en $\mathrm{PMN}$ provenientes de los ratones susceptibles, los cuales in vitro no habían mostrado ningún efecto fungicida contra las levaduras de P. brasiliensis (35).

Estos datos sugieren que los productos del estallido respiratorio constituyen uno de los mecanismos responsables del efecto antifúngico del PMN contra P. brasiliensis. Paradójicamente, la utilización de $M \phi$ peritoneales activados con citocinas como IFN- $\gamma$ (36), demostró que éstos ejercían un potente efecto fungicida contra las levaduras del hongo pero que tal mecanismo era independiente de los productos del estallido respiratorio. Recientemente, nuestro grupo (6) demostró que tal mecanismo fungicida era mediado por un reactivo intermediario del nitrógeno, el óxido nítrico. Esta diferencia podría deberse al tipo de célula y a los diferentes mecanismos de regulación de las vías metabólicas que caracterizan estas células.

Schaffner y colaboradores (37) estudiaron la susceptibilidad in vitro de algunos hongos dimórficos (virulentos) comparados con otros no patógenos (oportunistas) y encontraron que, a diferencia de los segundos, los patógenos primarios como Coccidioides immitis, Histoplasma capsulatum, Paracoccidioides brasiliensis, Blastomyces dermatitidis y Sporothrix schenkii, eran menos susceptibles al $\mathrm{H}_{2} \mathrm{O}_{2}$.

En referencia a otros hongos dimórficos, se ha demostrado que los productos del estallido respiratorio tienen algún efecto en la muerte del hongo, pero que, por el contrario, algunos de ellos logran inhibir o bloquear tal efecto. Por ejemplo, Galgiani $(38,39)$ demostró que existían diferencias en los varios estadios de $C$. immitis, ya que sus formas inmaduras se mostraban susceptibles al anión superóxido, pero no así las formas maduras (esférulas), las que, si bien estimulaban la producción de los reactivos intermediarios del oxígeno, interferían con la acción del $\mathrm{H}_{2} \mathrm{O}_{2}$ y del ácido hipocloroso $(\mathrm{HOCl})$. Es así como bajos niveles de estos oxidantes antimicrobianos podrían contribuir a la resistencia del hongo frente a los PMN humanos.

Brummer y colaboradores (40) demostraron también que la resistencia de $B$. dermatitidis a la muerte por PMN resulta de una ineficiente generación de productos del sistema microbicida dependiente de la peroxidasa. Contrario a este hallazgo es el informe de Morrison y colaboradores (41), quienes han sugerido que el aumento de la capacidad microbicida de PMN activados contra $B$. dermatitidis involucra uno o más mecanismos oxidativos y que el $\mathrm{O}_{2}$ - juega un importante papel, en forma directa o como precursor de otras especies activas de oxígeno, tales como $\mathrm{H}_{2} \mathrm{O}_{2}$, $\mathrm{IO}_{2}, \mathrm{HOCl}^{-}$y $\mathrm{OH}$.

Estudios con $H$. capsulatum han mostrado que la resistencía de este hongo a los mecanismos microbicidas del PMN, se consigue evadiendo los productos del estallido respiratorio y también la fusión fagolisosómica (42), independientemente de la capacidad del hongo para inducir los productos del estallido respiratorio.

Schnur y Newman (43) observaron que las levaduras de $H$. capsulatum estimulaban la producción de reactivos intermediarios del oxígeno producidos por los PMN, de acuerdo con la reducción intracelular del NBT (nitro blue tetrazolium), reducción del citocromo $\mathrm{C}$ en presencia de citocalacina $\mathrm{D}$, consumo de $\mathrm{O}_{2}$ y producción de $\mathrm{H}_{2} \mathrm{O}_{2}$, y que de una $\mathrm{u}$ otra forma, el hongo era capaz de evadir estos mecanismos destructivos.

En conclusión, las evidencias presentadas sugieren que el PMN participa activamente en la respuesta inflamatoria aguda inducida por $P$. brasiliensis, como se ha demostrado en los diferentes modelos descritos en esta revisión $(2,8,9,13,14,21-24)$. Algunos de los mecanismos 
exhibidos por esta célula fagocítica están mediados por los reactivos intermediarios del oxígeno, como ha sido evidenciado y como se ha correlacionado por el aumento en la quimioluminiscencia y la disminución del número de unidades formadoras de colonias (21-24). Igualmente, se ha demostrado el efecto activador de algunas citocinas sobre el PMN, en el que inducen un aumento en su capacidad antifúngica contra $P$. brasiliensis, mecanismo que se ha demostrado en otros modelos con C. albicans (30) y B. dermatitidis (32-34).

Los mecanismos moleculares responsables del efecto fungicida o fungistático del PMN frente a $P$. brasiliensis no son aún claros. Según las evidencias descritas en esta revisión, se sugiere que algunos productos del estallido respiratorio, así como la activación del PMN por acción de ciertas citocinas, participan, parcialmente al menos, en el efecto antifúngico contra $P$. brasiliensis demostrado en algunos casos por una disminución en el número de UFC o por un daño morfológico y estructural aparente. Sin embargo, existen estudios en este sentido con $H$. capsulatum, en los que Newman y colaboradores (27) observaron que el principal componente de la actividad fungistática contra este hongo dimórfico estaba localizado en los gránulos azurófilos de Ios PMN. Más recientemente, estos autores demostraron que tales gránulos están conformados por defensinas (péptidos antimicrobianos), la captesina $G$ y la proteína incrementadora de la permeabilidad bactericida (BPI), las cuales ejercían in vitro un efecto antifúngico dosis-dependiente (44).

Lo anterior sugiere que sería importante investigar sobre los mecanismos moleculares por los cuales el PMN ejerce su actividad antifúngica frente a $P$. brasiliensis para entender más precisamente la patogénesis de la interacción hospedero-parásito.

\section{Referencias}

1. Brummer E, Castañeda E, Restrepo A. Paracoccidioidomycosis: an update. Clin Microbiol Rev 1993;6:89117.

2. Cock AM, Cano LE, Vélez D, Aristizábal BH, Trujillo J, Restrepo A. Fibrotic sequelae in pulmonary paracoccidioidomycosis: histophatological aspects in $\mathrm{BALB} / \mathrm{C}$ mice infected with viable and non-viable
Paracoccidioides brasiliensis propagules. Inst Med Trop Sao Paulo 2000;42:59-66.

3. Restrepo S, Tobón A, Trujillo J, Restrepo A. Development and pulmonary fibrosis in mice during infection with Paracoccidioides brasiliensis conidia. $\mathrm{J}$ Med Vet Mycol 1992;30:173-84.

4. Restrepo S, Tobón A, Restrepo A. Celularidad del lavado broncoalveolar en la paracoccidioidomicosis experimental. Medicina UPB 1992;11:19-28.

5. Kashino SS, Fazioli RA, Moscardi-Bachi M, Franco $M$, Singer-Vermes LM, Burger E, et al. Effect of macrophage blockade on the resistant inbred mice to Paracoccidioides brasiliensis infection. Mycopathologia 1995; 130:131-40.

6. González A, De Gregori W, Vélez D, Restrepo A, Cano LE. Nitric oxide participation in the fungicidal mechanism of gamma interferon-activated murine macrophages against Paracoccidoides brasiliensis conidia. Infect Immun 2000;68:2546-52.

7. Abbas AK, Lichtman AH, Pober JS. Innate immunity. En: Abbas AK, Lichtman AH, Pober JS, editors. Cellular and molecular immunology. Philadelphia: W.B. Saunders Company; 2000. p.270-90.

8. Gesztesi JL, Dias MA, de Souza AR, de Almeida SR, Lopes JD, Mariano M. Subcutaneous infection of mice with Paracoccidioides brasiliensis induces a peculiar pattern of inflammatory and immune responses. Mycopathologia 1999;145:7-14.

9. Brummer E. Interaction of Paracoccidioides brasiliensis with host defense cells. En: Franco M, Lacaz CS, Restrepo-Moreno A, del Negro G, editores. Paracoccidioidomycosis. Boca Ratón: CRC Press; 1994. p.213-23.

10. Brito T, Franco MF. Granulomatous inflamation. Rev Inst Med Trop Sao Paulo 1994;36:185-92.

11. Kerr IB, Araripe JR, Oliveira PC, Lenzi HL. Paracoccidioidomycosis: a sequential histophatologic study of lesions in experimentally-infected rats. Rev Inst Med Trop Sao Paulo 1988;30:335-50.

12. Montenegro MR, Franco MF. Pathology. En: Franco M, Lacaz CS, Restrepo-Moreno A, del Negro G, editores. Paracoccidioidomycosis. Boca Ratón: CRC Press; 1994. p.131-50.

13. Bedoya V, McEwen JG, Tabares AM, Jaramillo FU, Restrepo A. Pathogenesis of paracoccidioidomycosis: a histopathological study of the experimental murine infection. Mycopathologia 1986;94:133-44.

14. Burger E, Miyaji M, Sano A, Calich VL, Nishimura K, Lenzi HL. Histopathology of paracoccidioidomycotic infection in athymic and euthymic mice: a sequential study. Am J Trop Med Hyg 1996;55:235-42.

15. Xidieh CF, Lenzi HL, Calich VL, Burger E. Influence of the genetic background on the pattern of lesions devel- 
oped by resistant and susceptible mice infected with Paracoccidioides brasiliensis. Med Microbiol Inmunol 1999;188:41-9.

16. Crott LS, Valim YM, Silva CL, Barbosa JE. The role of the complement system in the neutrophil functions stimulated in vitro by an alkali-insoluble cell wall fraction of Paracoccidioides brasiliensis. J Med Vet Mycol 1993; 31:17-27.

17. Crott LS, Lucisano-Valim YM, Silva CL, Barbosa JE. Interactions of $F 1$ fractions from different strains of Paracoccidioides brasiliensis with human complement and with human neutrophils. Mycopathologia 1997;140: 19-27.

18. San Blas G. The cell wall of fungal human pathogens: its possible role in host-parasite relationships. Mycopathologia 1982;79:159-84.

19. Silva CL, Alves LMC, Figueiredo F. Involvement of the cell wall glucans in the genesis and persistence of the inflammatory reaction caused by the fungus Paracoccidioides brasiliensis. Microbiology 1994;140: 1189-94.

20. Alves LM, Figueiredo F, Brandao Filho SL, Tincani I, Silva CL. The role of fractions from Paracoccidioides brasiliensis in the genesis of inflammatory response. Mycopathologia 1987;97:3-7.

21. McEwen JG, Brummer E, Stevens DA, Restrepo A. Effect of murine polymorphonuclear leukocytes on the yeast form of Paracoccidioides brasiliensis. Am J Trop Med Hyg 1987;36:603-8.

22. Kurita N, Oarada M, Ito E, Miyaji M. Antifungal activity of human polymorphonuclear leukocytes against yeast cells of Paracoccidioides brasiliensis. Med Mycol 1999; 37:261-7.

23. Kurita N, Oarada M, Miyaji M, Ito E. Effect of citokines on antifungal activity of human polymorphonuclear leukocytes against yeast cells of Paracoccidioides brasiliensis. Med Mycol 2000;38:177-82.

24. Kurita N, Biswas SK, Oarada M, Sano A, Nishimura K, Miyaji M. Fungistatic and fungicidal activities of murine polymorphonuclear leukocytes against yeast cells of Paracoccidioides brasiliensis. Med Mycol 1999;37:1924.

25. Brummer E, Sugar AM, Stevens DA. Immunological activation of polymorphonuclear neutrophils for fungal killing: studies with murine cells and Blastomyces dermatitidis in vitro. J Leukoc Biol 1984;36:505-20.

26. Morrison CJ, Brummer E, Stevens DA. Effect of a local immune reaction on peripheral blood polymorfonuclear neutrophil microbicidal function: studies with fungal targets. Cell Immunol 1987;110:176-82.

27. Newman SL, Gootee L, Gabay JE. Human neutrophilmediated fungistasis against Histoplasma capsulatum. Localization of fungistatic activity to the azurophil granules. J Clin Invest 1993;92:624-31.
28. Brummer E, Kurita N, Yoshida S, Nishimura K, Miyaji M. Fungistatic activity of human neutrophils against Histoplasma capsulatum: correlation with phagocytosis. J Infect Dis 1991;164:158-62.

29. Kurita N, Brummer E, Yoshida S, Nishimura K, Miyaji M. Antifungal activity of murine polymorphonuclear neutrophils against Histoplasma capsulatum. J Med Mycol 1991;29:133-43.

30. Ferrante A. Tumor necrosis factor alpha potentiates neutrophil antimicrobial activity: increased fungicidal activity against Torulopsis glabrata and Candida albicans associated increases in oxygen radical production and lysosomal enzyme release. Infect Immun 1989;57:211522.

31. Cano LE, Kashino SS, Arruda C, André D, Xidieh CF, Singer-Vermes LM, et al. Protective role of gamma interferon in experimental pulmonary paracoccidioidomycosis. Infect Immun 1998;66:800-06.

32. Morrison CJ, Brummer E, Stevens DA. In vivo activation of peripheral blood polymorphonuclear neutrophils by gamma interferon results in enhanced fungal killing. Infect Immun 1989;57:2953-8.

33. Morrison CJ, Stevens DA. Enhanced killing of Blastomyces dermatitidis by gamma interferon-activated murine peripheral blood polymorphonuclear neutrophils. Int $\mathrm{J}$ Immunopharmacol 1989;11:855-62.

34. Morrison CJ, Brummer E, Isenberg RA, Stevens DA. Activation of murine polymorphonuclear neutrophils for fungicidal activity by recombinant gamma interferon. J Leukoc Biol 1987;41:434-40.

35. Meloni-Bruneri LH, Campa A, Abdalla DS, Calich VL, Lenzi HL, Burger E. Neutrophil oxidative metabolism and killing of Paracoccidioides brasiliensis after air pouch infection of susceptible and resistant mice. $\mathrm{J}$ Leukoc Biol 1996;59:526-33.

36. Brummer E, Hanson LH, Stevens DA. Gamma interferon activation of macrophages for killing of Paracoccidioides brasiliensis and evidence for nonoxidative mechanism. Int J Immunopharm 1988;10: 945-52.

37. Schaffner A, Davis CE, Schaffner T, Markert M, Douglas H, Braude Al. In vitro susceptibility of fungi to killing by neutrophil granulocytes discriminates between primary pathogenicity and opportunism. J Clin Invest 1986;153:511-24.

38. Galgiani JN. Differences in oxidant release by human polymorphonuclear leukocytes produced by stimulation with different phases of Coccidioides immitis. J Infect Dis 1995;172:199-203.

39. Galgiani JN. Killing of Coccidioides immitis by hypochlorous acid or monochloramine. Med Vet Mycol 1990;28: 173-81.

40. Brummer E, Kurita N, Yoshida S, Nishimura K, Miyaji M. A basis for resistance of Blastomyces dermatitidis killing by human neutrophils: inefficient generation of 
myeloperoxidase system products. J Med Vet Mycol 1992;30:233-43.

41. Morrison CJ, Isenberg RA, Stevens DA. Enhanced oxidative mechanisms in immunologically activated versus elicited polymorphonuclear neutrophils: Correlations with fungicidal activity. Med Microbiol 1988; 25:115-21.

42. Kurita N, Terao K, Brummer E, Ito E, Nishimura K, Miyaji M. Resistance of Histoplasma capsulatum to killing by human neutrophils. Evasion of oxidative burst and lysosomal-fusion products. Mycopathologia 1991; 115:207-13.

43. Schnur RA, Newman SL. The respiratory burst response to Histoplasma capsulatum by human neutrophils. Evidence for intracellular trapping of superoxide anion. J Immunol 1990;144:4765-72.

44. Newman SL, Gootee L, Gabay JE, Selsted ME. Identification of constituents of human neutrophil azurophil granules that mediate fungistasis against Histoplama capsulatum. Infect immun 2000;68:5668-72. 


\title{
Factores genéticos y su influencia en las micosis sistémicas
}

\author{
María del Pilar Jiménez 1,2, Luis F. García ${ }^{2}$, Luz E. Cano 1,3, Angela Restrepo ${ }^{1}$ \\ 1 Grupo de Micología Médica y Experimental, Corporación para Investigaciones Biológicas, Medellín, \\ Colombia. \\ ${ }^{2}$ Grupo de Inmunología Celular e Inmunogenética, Facultad de Medicina, Universidad de Antioquia, Medellín, \\ Colombia. \\ ${ }^{3}$ Escuela de Bacteriología y Laboratorio Clínico, Universidad de Antioquia, Medelín, Colombia.
}

La respuesta defensora del hospedero frente a la infección microbiana depende de múltiples mecanismos, entre los cuales las características genéticas del hospedero juegan papel importante, ya que condicionan tanto la resistencia natural como la adquirida. La mayoría de hallazgos en este campo en micosis sistémicas, se ha evidenciado en el modelo animal. En estas enfermedades, uno de los componentes genéticos más estudiados ha sido el complejo mayor de histocompatibilidad (CMH). Sin embargo, en ratones consanguíneos no se ha demostrado la existencia de una relación entre estos genes y la respuesta inmune desencadenada contra los agentes causales de tales micosis. Con relación a otros factores, como el sistema del complemento, se ha podido establecer una asociación solamente en el caso de la criptococosis. En cepas consanguíneas de ratón, los patrones de resistencia y susceptibilidad a Cryptococcus neoformans dependen de la presencia o ausencia del gen correspondiente, $\mathrm{C}^{1}$ o $\mathrm{C}^{0}$, respectivamente. Por otra parte, en un buen número de las micosis que se mencionan, se ha demostrado que la respuesta inmune mediada por células, es fundamental para su control. En la coccidioidomicosis y la paracoccidioidomicosis, la función de las células $T$ es decisiva, a diferencia de lo observado en candidiasis, en la cual la principal célula efectora parece ser el polimorfonuclear. En cuanto al patrón de citocinas, se ha observado que los ratones susceptibles a Coccidioides immitis o Paracoccidioides brasiliensis, al ser infectados con estos hongos, producen predominante y tempranamente citocinas tipo TH2, IL-10 e IL-4 en coccidioidomicosis e IL-10 e IL-5 en paracoccidioidomicosis. En la histoplasmosis, los estudios han señalado la importacia del IFN $\gamma$ en la defensa. Hasta el presente, sólo se conocen genes específicos que determinan la respuesta inmune en la candidiasis, Carg1 y Carg2. En la coccidioidomicosis, se han sugerido dos genes, Cms1 y Cms2. En las micosis que se describen a continuación, el gen o los genes que condicionarían la respuesta correspondiente son de tipo autosómico y el fenotipo de resistencia es el dominante. En esta revisión se analizan ciertos aspectos de la constitución genética del hospedero que condicionan la respuesta inmune frente a los agentes causales de las micosis sistémicas y se señalan las similitudes y las diferencias entre ellos.

Palabras clave: factores genéticos, micosis sistémicas, resistencia, susceptibilidad.

\section{Genetic factors and their influence in systemic micoses}

The host's immune response to pathogenic microorganisms depends on several mechanisms. Genetic characteristics of the host clearly impact on the host's natural and immune resistance status. In systemic mycoses, most of the evidence has been obtained from animal models. For example, no relation has been observed between the genes linked to the major histocompatibility complex (MHC) and the immune response to fungi. With respect to complement factors, an association with only cryptococcosis has been established. In this case, resistance and susceptibility patterns in inbred mice depend on the presence or absence of this gene $\left(\mathrm{C}^{1}\right.$ or $\mathrm{C}^{0}$, respectively). For most of the mycoses reviewed here, however, the immune response mediated by cells is considered crucial for control of the disease process. In coccidioidomycosis and paracoccidioidomycosis, $\mathrm{T}$ cell function is decisive. This contrasts with candidiasis, where the most important cell is the polymorphonuclear (PMN). The cytokine pattern in infected mice sus- 
ceptible to $C$. immitis and $P$. brasiliensis produce primarily TH2 cytokines - IL-10 and IL-4 - in coccidioidomycosis, and IL-10 and IL-5 in paracoccidioidomycosis. In histoplasmosis, IFN $\gamma$ plays a significant role. At present, specific genes responsible for the immune response have been reported only for candidiasis (Carg1 and Carg2). In coccidioidomycosis, two genes, Cms1 and $\mathrm{Cms2}$, have been suggested. For the mycoses reviewed here, the gene or genes that influence immune responses are autosomic and their resistance phenotype is dominant.

Key words: genetic factors, systemic mycoses, resistance, susceptibility.

La respuesta defensiva del hospedero frente a los microorganismos, sean ellos bacterianos, virales, parasitarios o fúngicos, depende de la combinación de múltiples mecanismos, los que incluyen medidas de defensa naturales (innatas) o inmunes (adquiridas). Las características genéticas del hospedero influyen en estos dos tipos de respuesta y, por ende, determinan la resistencia o susceptibilidad a las enfermedades infecciosas (1).

La importancia de los factores genéticos en humanos se ha demostrado a través de estudios en gemelos e hijos adoptivos (2,3). Sin embargo, la mayoría de los hallazgos se ha verificado en modelos animales, en los que es factible controlar el fenotipo de la enfermedad, los factores medioambientales y la influencia de los cruces. En esta forma, se facilita el análisis de los rasgos complejos involucrados en la resistencia o susceptibilidad a un determinado patógeno infeccioso (4).

Las siguientes son algunas de las evidencias disponibles en el momento:

- Asociaciones con ciertos alelos del complejo mayor de histocompatibilidad ( $\mathrm{CMH}$ ) clase II en lepra $(5,6)$, malaria $(7)$ y hepatitis $B(8,9)$.

- Polimorfismos en promotores de genes que expresan proteínas de importancia para la respuesta inmune, tales como el factor de necrosis tumoral $\alpha$ (TNF $\alpha$ ), en lepra (10), malaria (11), leishmaniasis mucocutánea (12) y en la muerte por enfermedad meningocóccica (13). El gen que expresa el TNF $\alpha$ está localizado dentro del MHC y ello podría influir en algunas de las

\section{Correspondencia:}

M.P. Jiménez

Calle 9A Sur No. 25-33, apartamento 205, Medellín utria@epm.net.co.

Recibido: 16/02/01; aceptado: 29/06/01 asociaciones observadas entre antígenos HLA y ciertas enfermedades infecciosas.

Igualmente, los estudios realizados sobre las mutaciones de los receptores para citocinas en familias que presentan susceptibilidad recesiva a micobacterias atípicas han permitido observar que dicha susceptibilidad está asociada a la ausencia del receptor para el interferón $\gamma$ (IFN $\gamma$ ) en los leucocitos de los pacientes $(14,15)$. En otros estudios realizados en pacientes con tuberculosis, se han encontrado también polimorfismos en los genes para el antagonista del receptor de la IL-1 y la IL-1 $\beta$ (16).

- Polimorfismos en los receptores de la vitamina $\mathrm{D}$, los que se asocian con aumento en la susceptibilidad a Mycobacterium tuberculosis y a la infección por el virus de la hepatitis B (6).

- Mutaciones en la proteína lectina ligadora de manosa (MBL), que juega un papel importante en la inmunidad innata. Se ha encontrado que estas mutaciones están asociadas con un buen número de infecciones (17).

- Hallazgo de genes involucrados directamente en la respuesta inmune, como es el Nramp1, que en ratones controla la susceptibilidad innata a varias especies de micobacterias y a otros microorganismos intracelulares no relacionados, al menos durante la fase temprana de la infección (18-21). En los ratones, este gen se encuentra localizado en la región proximal del cromosoma $1(21,22)$. En humanos, ha sido posible localizar, secuenciar y clonar un gen homólogo al Nramp1 murino, denominado NRAMP1, que se encuentra ubicado en el brazo largo del cromosoma $2(23,24)$. Este gen codifica para la proteína denominada 'proteína 1 del macrófago asociada con la resistencia natural' (19), que se expresa en el fagosoma (25) de células de la línea mieloide (26). Al gen Nramp1/NRAMP1 se le ha atribuido una gran 
variedad de efectos pleiotrópicos que, en último término, regulan una cascada de eventos que median la inflamación y la eliminación de microorganismos invasores (27). En un estudio hecho en personas del sureste asiático, se demostró que el NRAMP1 es uno de los genes que contribuye en esta población a la susceptibilidad genética a la lepra (28).

\section{Micosis y factores genéticos}

La mayoría de los hongos que causan enfermedad en el hombre se encuentran en el ambiente y como tal pueden considerarse como saprofitos; sólo son patógenos aquéllos que logran adaptarse al cuerpo humano y sobrevivir en el ambiente inhóspito de los tejidos (29). Como ejemplo podrían mencionarse los hongos dimórficos patógenos para el hombre como Histoplasma capsulatum, Coccidioides immitis, Blastomyces dermatitidis, Paracoccidioides brasiliensis y Sporothrix schenckii, que tienen su hábitat natural en el suelo o están asociados con la vegetación, pero que se adaptan a los tejidos humanos y pueden producir enfermedad. Gracias al dimorfismo, estos hongos pueden crecer en forma saprofita a $25{ }^{\circ} \mathrm{C}$ y desarrollarse también a $37^{\circ} \mathrm{C}$ para cambiar de forma en los tejidos. La habilidad de los hongos dimórficos para transformarse de saprofitos en parásitos les permite sobrevivir y multiplicarse en los tejidos de su accidental hospedero, en el cual suelen producir enfermedades sistémicas de variada severidad (1).

Actualmente, se dispone de ciertas evidencias obtenidas principalmente de modelos en ratones consanguíneos sobre la influencia que los factores genéticos juegan en la resistencia o susceptibilidad a ciertas micosis sistémicas.

\section{Influencia del complejo mayor de histocompatibilidad (CMH)}

Existen evidencias de tipo epidemiológico sobre el riesgo que representan diferentes poblaciones humanas en la diseminación de la infección primaria por $C$. immitis; tal riesgo es 5 a 20 veces mayor en personas negras y también en filipinos (30). Se ha comprobado que en estos grupos étnicos, el antígeno HLA A9 del CMH y el grupo sanguíneo $B$ son más frecuentes que en personas caucásicas, lo que explicaría la frecuencia de la coccidioidomicosis diseminada en los primeros (31).

Los experimentos realizados por Kirkland y Fierer (32) con cepas consanguíneas de ratones $\mathrm{BALB} / \mathrm{C}$ y DBA/2N, que comparten el haplotipo $\mathrm{H}-2^{\mathrm{d}}$, revelaron que al ser infectados con $C$. immitis, los ratones $\mathrm{DBA} / 2 \mathrm{~N}$ eran 1.000 veces más resistentes a la infección que los BALB/c. Se demostró así que la resistencia era el fenotipo dominante y que no estaba determinada por el $\mathrm{CMH}$ (32).

En la paracoccidioidomicosis, la influencia de diferentes poblaciones humanas es difícil de estimar debido a la frecuente mezcla de diversos grupos raciales entre los habitantes de áreas endémicas (33). Sin embargo, en un estudio realizado en Brasil, se encontró que el antígeno HLA-B40 primaba en los pacientes y que su presencia aumentaba el riesgo de padecer la enfermedad $(34,35)$. Previamente se había informado que en pacientes colombianos predominaban los antígenos HLA-A9 y HLA-B13. Esta diferencia podría deberse a las diferentes constituciones genéticas de las poblaciones estudiadas (36). En un trabajo diferente, Demessias y colaboradores encontraron que productos de la clase III del $\mathrm{CMH}$, especialmente el C4B-00, estaban asociados con enfermedad crónica, una circunstancia que podría influir en el curso de la infección (37).

En un modelo murino de paracoccidioidomicosis por vía intraperitoneal, se estudiaron once cepas consanguíneas y se observaron varios patrones de susceptibilidad de acuerdo con la mortalidad. Se definieron cuatro patrones básicos, medidos en la supervivencia: susceptibles (B10.D2/oSn, B10A, B10D2/nSn), con susceptibilidad intermedia (BALB/c, C57BL/10, CBA, C3H/Fe), resistentes $(\mathrm{C} 3 \mathrm{H} / \mathrm{HeJ})$ y muy resistentes $(\mathrm{A} / \mathrm{Sn}$, $\mathrm{A} / \mathrm{J}, \mathrm{DBA} / 2$ ). Los resultados mostraron que las diferencias en la susceptibilidad no eran controladas por el $\mathrm{H}-2$, ya que tanto la cepa más susceptible (B10A) como la más resistente (A/ $\mathrm{Sn})$, compartían el mismo haplotipo $\mathrm{H}-2^{\mathrm{a}}(38)$.

Un análisis de cepas de ratones consanguíneos y congénicos, demostró que la resistencia/ susceptibilidad a Candida albicans, estimada por 
la severidad de las lesiones tisulares y la intensidad del compromiso de los nódulos linfáticos, estaba determinada por genes localizados por fuera del $\mathrm{CMH}$, ya que la cepa más resistente $(B A L B / c)$, así como la más susceptible $(\mathrm{CBA} / \mathrm{H})$, tenían los mismos genes $\mathrm{CMH}$, $\mathrm{H}-2^{\mathrm{k}}(39)$.

En la histoplasmosis, los estudios experimentales de Chick y Roberts, realizados en ratones consanguíneos, mostraron variaciones en la susceptibilidad. La cepa C57BL/10 fue la más susceptible y la $\mathrm{A} / \mathrm{J}$, la más resistente, a pesar de que ambas poseen haplotipos $\mathrm{CMH}$ idénticos (40).

En un modelo murino de blastomicosis por vía intranasal, se observó que la cepa $\mathrm{C} 3 \mathrm{H} / \mathrm{HeJ}$ era la más susceptible y la $\mathrm{DBA} / 1 \mathrm{~J}$ la más resistente. Las diferencias significativas observadas entre estas cepas, se mantuvieron a pesar de variar el tamaño del inóculo. Tampoco fueron dependientes de la cepa de B.dermatitidis, de la edad del hospedero o de la habilidad del inóculo para penetrar a las vías aéreas inferiores, ni tampoco de la relación con los locus H-2 (41). Posteriormente, por inoculación intraperitoneal, se observaron resultados inversos. En efecto, al infectar los ratones con la cepa atenuada y la virulenta del hongo, se encontró que los ratones DBA/1J presentaban mayores porcentajes de mortalidad que los $\mathrm{C} 3 \mathrm{H} / \mathrm{HeJ}, 75$ y $8 \%$ con la cepa atenuada y 100 y $25 \%$ con la cepa virulenta, respectivamente. No fue posible encontrar en este mismo trabajo una correlación entre los patrones de resistencia y de susceptibilidad con el haplotipo $\mathrm{H}-2$, tal como se había observado en otras micosis sistémicas (42). El cuadro 1 presenta un resumen de los hallazgos mencionados.

\section{Genes involucrados}

En la coccidioidomicosis, se realizó un trabajo (44) con el objeto de analizar la progenie de retrocruzamientos (BALB/C $\times D B A / 2) ~ F 1 \times B A L B / C$ y (C57BL/6×DBA/2) F1 $\times$ C57BL/6, machos $y$ hembras, con el fin de determinar el número de genes que controlaban la resistencia. Se encontró una distribución 1:1 de progenies resistentes y susceptibles en ambos retrocruzamientos. Este hallazgo es consistente con la hipótesis de que un solo gen es el determinante de la resistencia a esta micosis. Los hallazgos provenientes de diferentes estudios han llevado a sugerir que en la coccidioidomicosis murina la resistencia es el fenotipo dominante y está determinada por un gen designado hipotéticamente $\mathrm{Cms}$ (44). El papel exacto de la expresión del gen $\mathrm{Cms}$ en la resistencia a esta micosis es aún desconocido; sin embargo, no parece influir en los mecanismos innatos de resistencia celular, ya que sus efectos son más notables diez días después de la infección $(31,43,44)$. Por otra parte, se encontraron más ratones susceptibles entre los machos que entre las hembras, lo cual no anula lo anterior ya que el gen de resistencia no está ligado al cromosoma X (48).

Con el fin de establecer los genes responsables de la resistencia a la coccidioidomicosis en el modelo murino, recientemente se realizaron

Cuadro 1. Susceptibilidad y resistencia de diferentes cepas de ratones a ciertos hongos.

\begin{tabular}{|c|c|c|c|c|c|c|c|c|}
\hline \multirow[b]{2}{*}{$\begin{array}{l}\text { Agente } \\
\text { micótico }\end{array}$} & \multicolumn{7}{|c|}{ Cepa de ratón: H-2 (KAED) } & \multirow[b]{2}{*}{ Referencias } \\
\hline & $\begin{array}{l}\text { BALB/c } \\
\text { (dddd) }\end{array}$ & $\underset{(k k k d)}{A}$ & $\begin{array}{c}\text { C57BL/6 } \\
\mathrm{O} \\
\text { C57BL/10 } \\
\text { (bb-b) }\end{array}$ & $\begin{array}{c}\text { CBA } \\
\text { (kkkk) }\end{array}$ & $\begin{array}{l}\text { * DBA/2 } \\
\text { (dddd) }\end{array}$ & $\begin{array}{c}\text { B10A } \\
\text { (kkkk) }\end{array}$ & $\begin{array}{c}\mathrm{C} 3 \mathrm{H} / \mathrm{HeJ} \\
(\text { kkkk) }\end{array}$ & \\
\hline C. immitis & S & $S$ & S & । & $\mathrm{R}$ & & & $32,43,44$ \\
\hline P. brasiliensis & 1 & $\mathrm{R}$ & 1 & I & $\mathrm{R}$ & $\mathrm{S}$ & $\mathrm{R}$ & 38 \\
\hline C. albicans & $\mathrm{R}$ & I & $\mathrm{R}$ & $S$ & $\mathrm{~S}$ & & & $39,45,46$ \\
\hline H. capsulatum & N/D & $\mathrm{R}$ & S & $\mathrm{N} / \mathrm{D}$ & $N / D$ & & & 47 \\
\hline C. neoformans & 1 & S & $\mathrm{R}$ & I-R & $S$ & & & 48 \\
\hline B. dermatitidis & & & & ${ }^{*} \mathrm{DBA} / 1 \mathrm{~J}$ & $\mathrm{R}$ & & $\mathrm{S}$ & 41,42 \\
\hline
\end{tabular}

N/D: no determinada; R: resistente; S: susceptible; I: susceptibilidad intermedia 
experimentos en 26 líneas de ratones consanguíneos recombinantes, derivados del cruce entre ratones BLACK 6 y DBA/2. Los ratones se infectaron por vía intraperitoneal y 15 días más tarde se cuantificó el número de unidades formadoras de colonias del hongo en bazo y pulmones, así como la cantidad de ARNm para IL-10 en tejido pulmonar. Se encontró que las asociaciones más significativas ocurrían entre las regiones cercanas al locus $L v$ (aminolevulinato deshidratasa) en el cromosoma 4 y en el locus Tnfr1 (receptor para el factor de necrosis tumoral murino tipo 1) del cromosoma 6 . En los ratones producto del retrocruzamiento F2 [(BLACK $6 \times \mathrm{DBA} / 2) \times B L A C K 6$ ] se confirmó la presencia de tales asociaciones. Fue así como 14 de 16 ratones (87\%) heterocigóticos tanto para $L v$ como para Tnfr1, mostraron ser resistentes a la infección, mientras que sólo 4 (25\%) de los BLACK6 homocigóticos para ambos locus resultaron ser resistentes. Estos son los primeros loci que se encuentran asociados con la resistencia al $C$. immitis y fueron denominados $C m s 1$ y $C m s 2$, respectivamente. Sin embargo, los resultados sugieren que la resistencia a $C$. immitis es un rasgo poligénico, así que pueden existir otros genes adicionales involucrados en la resistencia a esta infección (50) (cuadro 2).

En estudios realizados en la paracoccidioidomicosis con las progenies F1, F2 y la de retrocruzamiento de ratones resistentes $(\mathrm{A} / \mathrm{S} n)$ y susceptibles (B10.A), se ha observado que la resistencia está ligada a un gen autosómico dominante, el cual se designó hipotéticamente como $\mathrm{Pbr}$ (51).

En el caso de $C$. albicans, los estudios de cepas murinas congénicas resistentes y susceptibles, infectadas con el hongo, revelaron que el tiempo de supervivencia se correlacionaba sólo con dos patrones de daño tisular, leve y severo (52). El estudio en los híbridos F1 y F2 proporcionó evidencia clara de tipo mendeliano sobre la existencia del gen Carg1 (53), que se consideró encargado de determinar la extensión de la destrucción tisular. La vía por la cual este gen ejerce su efecto no ha sido aún definida, pero a medida que se disminuye el número de neutrófilos, desaparecen las diferencias específicas de cepa
Cuadro 2. Genes asociados con micosis sistémicas en estudios de ratones consanguíneos recombinantes.

\begin{tabular}{|c|c|c|c|}
\hline Agente & Cromosoma & $\begin{array}{l}\text { Genes con los } \\
\text { que se asocian }\end{array}$ & $\begin{array}{r}\text { Genes } \\
\text { (ref.) }\end{array}$ \\
\hline \multirow[t]{2}{*}{ c. immitis } & 4 & $\begin{array}{c}\qquad v \\
\text { (deshidratasa } \\
\text { aminolevulinato) }\end{array}$ & $\begin{array}{c}\text { Cms1 } \\
(50)\end{array}$ \\
\hline & 6 & $\begin{array}{l}\text { Tnfr1 } \\
\text { (receptor para el } \\
\text { factor de necrosis } \\
\text { tumoral murino tipo 1) }\end{array}$ & $\begin{array}{c}\text { Cms2 } \\
(50)\end{array}$ \\
\hline \multirow[t]{2}{*}{ C. albicans } & 14 & $\begin{array}{c}\text { Rib1 } \\
\text { (ribonucleasa } \\
1 \text { pancreática) }\end{array}$ & $\begin{array}{c}\text { Carg1 } \\
(53,54)\end{array}$ \\
\hline & & Tcra & $\begin{array}{c}\text { Carg2 } \\
(53)\end{array}$ \\
\hline
\end{tabular}

en lo concerniente a la severidad de la lesión (53). Se realizaron estudios posteriores para evaluar el patrón de daño tisular (riñón y cerebro), resultante de la infección intravenosa con blastoconidias de C. albicans en cepas consanguíneas recombinantes, AKXL, derivadas de progenitores AKR, deficientes y normales en el componente C 5 del complemento. Se identificaron así tres patrones de daño tisular, a saber, pielonefritis de severidad moderada como en las AKR; de severidad leve como la observada en la cepa C57/L, y de severidad mayor que en la AKR. Los cerebros de estos ratones mostraron patrones de destrucción tisular similar a los descritos en el tejido renal. Nueve de 15 cepas mostraron daño tisular leve (igual que C57/L), 2 desarrollaron lesiones comparables a las de la cepa parental AKR y 4 presentaron un patrón de lesión más severo. Estos resultados sugirieron que era posible atribuir la severidad de las lesiones a la acción de dos genes independientes, designados genes de resistencia a C. albicans 1 y 2 (Carg1 y Carg2) (53).

En un grupo de cepas consanguíneas de ratones recombinantes, se analizó la distribución del gen de resistencia para $C$. albicans (Carg1), así como los marcadores del segmento de ADN. Se observó que 13 de 15 cepas exhibían reciprocidad para Carg1, Tcra y Rib1 (ribonucleasa 1, pancreática). Lo anterior sugiere que el gen Carg1 está localizado en el cromosoma 14 del ratón (54) (cuadro 2). 
En la histoplasmosis, varios genes parecen estar involucrados en la respuesta inmune, como se demostró en un estudio en el que se ensayaron 15 cepas de ratones consanguíneos y en el cual se observó que la variación era continua de cepa a cepa, sin segregación clara de fenotipos de susceptibilidad/resistencia, tal como se había observado en los progenitores (55).

\section{Tipo de célula encargada de la respuesta inmune}

Inicialmente, $C$. immitis produce una infección localizada que progresa para diseminarse posteriormente y causar la muerte de los ratones $\mathrm{BALB} / \mathrm{c}$ en menos de cuatro semanas; esto sugiere que los animales de esta cepa no desarrollan una respuesta inmune efectiva durante la infección. Pero, a pesar de su susceptibilidad para desarrollar infección diseminada y fatal, estos ratones logran ser inmunizados exitosamente con C. immitis y, después de la inmunización, sus células T responden in vitro al antígeno homólogo, que resulta en la obtencion de protección contra un nuevo reto (32).

El anterior modelo de coccidioidomicosis ofrece varias semejanzas con la enfermedad humana. En ambos casos, la resistencia está relacionada con la habilidad del hospedero para confinar la infección al sitio de entrada; por el contrario, las infecciones letales son el resultado de la diseminación progresiva. Tanto los ratones resistentes como los susceptibles responden al hongo con la formación de granulomas, lo cual los hace indistinguibles de la respuesta humana (32).

Se ha observado, además, que la resistencia a $C$. immitis puede anularse por irradiación, lo cual indica que es necesario tener células en división, a diferencia de la resistencia determinada por el locus $B c g / N r a m p 1$, que es resistente a la irradiación (49). En un estudio anterior, se había observado que los ratones de la cepa DBA/2 (resistentes) carentes de células $T$ efectivas, tal como sucede en ratones atímicos o timectomizados por irradiación, eran susceptibles a un inóculo no letal para sus contrapartes heterocigotos o controles irradiados pero con timo (56). Así, el hecho de que los ratones deficientes en células T sean más susceptibles a la infección que los ratones con función normal de estas células, sugiere que estas últimas son necesarias para la respuesta inmune frente a C. immitis (44).

En la paracoccidioidomicosis, se estudió el papel desempeñado por las células T en ratones BALB/ c atímicos (nu/nu) y eutímicos (nu/+). Ambas cepas de ratones fueron infectados con el aislamiento $\mathrm{Pb} 18$ (virulento) y como respuesta los $n u / n u$ presentaron una infección mucho más severa que los ratones ( $n u /+$ ), evidenciada en el primer grupo por un mayor número de órganos afectados y tiempos de supervivencia más cortos (57). En cuanto a la importancia del sistema fagocítico mononuclear en la defensa contra $P$. brasiliensis, se ha observado que, aunque los ratones resistentes y susceptibles despliegan similar aflujo celular, la respuesta del macrófago es significativamente mayor en los $\mathrm{A} / \mathrm{Sn}$ (51). En efecto, los macrófagos de los ratones resistentes $\mathrm{A} / \mathrm{Sn}$ muestran una capacidad superior para expandirse y adherirse y producir mayores concentraciones de peróxido de hidrógeno (58). Se ha evaluado también en ratones B10.A y A/ $\mathrm{Sn}$, inoculados intraperitonealmente con $\mathrm{Pb} 18$, la expresión de antígenos $\mathrm{CMH}$ clase II (Ia) por células peritoneales adherentes, en diferentes tiempos postinfección. Se encontró que la expresión de estos antígenos aumentaba en ambas cepas murinas, siendo mayor en las primeras horas para los ratones B10.A susceptibles. Sin embargo, cuando las células adherentes de ambas cepas se incubaban 48 horas, los niveles de antígeno disminuían en los ratones susceptibles, pero no en los ratones $A /$ $\mathrm{Sn}$. En esta forma, la infección con $P$. brasiliensis induce una expresión sostenida de las moléculas $\mathrm{CMH}$ clase II en los macrófagos peritoneales de los ratones resistentes y una expresión transitoria en aquéllos de los animales susceptibles. EI comportamiento diferente de las cepas resistentes y susceptibles frente a la infección con $P$. brasiliensis sugiere que diferentes mecanismos están comprometidos en la expresión de antígenos $\mathrm{CMH}$ clase II (59).

En un estudio posterior, se evaluaron los macrófagos broncoalveolares de pacientes con paracoccidioidomicosis por medio de técnicas de 
inmunomarcación y se demostró que la expresión de moléculas $\mathrm{CMH}-$-ll estaba disminuida; ello podría relacionarse con una menor capacidad en la presentación de antígenos por los macrófagos alveolares (60). En un trabajo reciente (61), ratones de la cepa C57BL/6 que poseen susceptibilidad intermedia a $P$. brasiliensis, se infectaron con el hongo y se observó que la expresión del antígeno Ia en macrófagos estaba disminuida, con ligeras variaciones de acuerdo con la vía de inoculación y cepa del hongo utilizada. La supresión de la expresión de la y la disminución en las respuestas proliferativas de células esplénicas, se correlacionaron con las concentraciones de óxido nítrico (NO). Estos parámetros fueron revertidos al suministrarle a los animales nitro-L-arginina, lo que resultó en falta de producción de NO. Se demostró así, que la expresión del antígeno Ia está modificada en la infección por $P$. brasiliensis y se correlaciona con la producción de NO (61).

Los resultados obtenidos después de infectar ratones congénicos resistentes ( $A / S n$ ) y susceptibles (B10.A) por vía intratraqueal, sugieren que la susceptibilidad a la infección pulmonar por $P$. brasiliensis está asociada con defectos en la activación de los macrófagos alveolares, con bajos niveles de hipersensibilidad retardada $y$, adicionalmente, con una producción elevada de anticuerpos específicos (62).

En experimentos in vitro realizados con el objeto de evaluar el metabolismo oxidativo y la muerte de $P$.brasiliensis por neutrófilos obtenidos de ratón $A / J$ (resistentes) y susceptibles (B10.A), se observó que los neutrófilos de los primeros producían mayor cantidad de reactivos intermediarios del oxígeno (ROIS) e inhibían el crecimiento del hongo de acuerdo con la reducción en el número de UFC (63).

Los eventos celulares tempranos en cepas resistentes $(A / S n)$ y susceptibles $(B 10 . A)$ frente a la infección por $P$. brasiliensis, se caracterizan en ambas por una marcada infiltración de neutrófilos, siendo mayor en los B10.A. Con el fin de investigar los eventos tempranos de la respuesta inflamatoria frente a la infección por $P$. brasiliensis, éste fue inoculado en la almohadilla plantar de ratones resistentes (A/Sn) y susceptibles (B10.A). Se encontró que si antes de la infección se disminuía el número de neutrófilos en ambas cepas de ratón, dicho tratamiento influía diferencialmente en la cinética del proceso inflamatorio, pero sin modificar la carga fúngica en las lesiones; ocurría disminución en la respuesta de hipersensibilidad retardada y aumento en los títulos de anticuerpos totales antigp43. En ratones desnudos sí se notó un incremento de la carga fúngica en las lesiones. Esto indica que la infección autolimitada resultante de la inoculación en tejidos subcutáneos corresponde a un fenómeno dependiente de células T (64).

Para comparar la evolución secuencial de las lesiones desarrolladas por ratones resistentes $(A)$ $\mathrm{Sn})$ y susceptibles (B10.A) como resultado de la infección por $P$. brasiliensis, mensualmente desde el primer hasta el sexto mes postinfección, el páncreas y el epiplón peripancreático se retiraron para estudio. En ambas cepas, las lesiones se localizaron principalmente en el epiplón mientras que en ratones $B 10$.A unas pocas se observaron en el parénquima pancreático. En todas las lesiones y en ambas cepas murinas predominaron macrófagos y plasmocitos, seguidos por neutrófilos y macrófagos transformados en células gigantes y epitelioides. Se observaron diferencias importantes entre ratones resistentes y susceptibles en cuanto a la estructura de la matriz extracelular de las lesiones granulomatosas. En los ratones $\mathrm{A} / \mathrm{S} n$, después de transcurrido el primer mes, coexistían dos tipos de lesiones: una consistente en nódulos encapsulados bien definidos, constituidos principalmente de colágeno tipo I con abundantes neutrófilos localizados en áreas donde había destrucción fúngica masiva y con presencia también de algunas levaduras viables, y el otro tipo de lesión correspondió a unos pocos depósitos de colágeno y presencia de macrófagos de aspecto xantomatoso, que contenían detritos del hongo. Estas lesiones predominaron después del segundo mes de infección y a partir del cuarto y fueron las únicas observadas, lo que indicaba el control de la infección. En los ratones B10.A, por el contrario, se observó un solo tipo de lesión, con menor 
tendencia a la encapsulación y con formación de múltiples focos granulomatosos pequeños, individualizados por fibras de colágeno reticular tipo III, con abundantes plasmocitos en la periferia y gran número de levaduras multigemantes, sin evidencia de destrucción fúngica. En el transcurso de la infección, las lesiones incrementaron progresivamente en número y tamaño. Estos hallazgos histopatológicos demuestran la influencia de la constitución genética del hospedero en el desarrollo de la paracoccidioidomicosis (65).

En la candidiasis, se estudió la posibilidad de correlacionar directamente la respuesta inmune mediada por células con la resistencia/ susceptibilidad a la infección. Para ello, se realizaron experimentos en los que se determinó la migración de linfocitos a ganglios linfáticos poplíteos después de la inoculación subcutánea de $C$. albicans en las almohadillas plantares de los ratones. En las etapas iniciales, se encontró que los ratones BALB/c presentaban una respuesta mayor y más prolongada en los ganglios linfáticos poplíteos que los animales susceptibles $\mathrm{CBA} / \mathrm{H}$ (39). Sin embargo, cuatro días después de la inoculación, la proporción de células $T$ en los nódulos activados era mayor en los ratones $\mathrm{CBA} / \mathrm{H}$ que en los BALB/c. Después de la inmunización, la actividad en tales nódulos disminuía y no difería significativamente entre las dos cepas (66). En ambas, por el contrario, la respuesta inmune mediada por células era diferente; a las 24 y 48 horas, los ratones resistentes (BALB/c) presentaban respuestas de hipersensibilidad retardada significativas mientras que los ratones $\mathrm{CBA} / \mathrm{H}$ no lo hacían así. Para comprobar lo anterior, se realizaron pruebas de proliferación de linfocitos in vitro, en las cuales se encontró que los BALB/c mostraban una proliferación más temprana y mayor que los CBA/ $\mathrm{H}$. La menor actividad en estos animales susceptibles no se debía a un defecto sistémico de la inmunidad mediada por células, ya que las respuestas proliferativas a un mitógeno de células T fueron casi idénticas en las dos cepas de ratones (66).

Con el fin de determinar si la resistencia era debida a células derivadas de la médula ósea, se construyeron quimeras por irradiación letal de cepas susceptibles $(\mathrm{CBA} / \mathrm{H})$, las que posteriormente fueron reconstituidas con células de médula ósea provenientes de ratones singénicos resistentes, previamente infectados con una dosis subletal de $C$. albicans. Se observó que los ratones susceptibles habían sido protegidos, lo cual indicaba que las células que influían en la resistencia natural, al menos en el estadio temprano de la infección, eran de vida corta y ellas (o sus precursoras) eran radiosensibles y derivadas de la médula ósea.

Por su parte, las células efectoras fueron, probablemente, leucocitos polimorfonucleares (PMN), lo cual parece consistente con la demostración de una susceptibilidad aumentada a la candidiasis sistémica en ratones mutantes beige, los cuales tienen un defecto en la generación de PMN (66). Como se anotó anteriormente, es probable que la magnitud del daño tisular esté ligada a respuestas inflamatorias mediadas por el neutrófilo (53). Igualmente, las actividades fagocíticas y fungicidas ejercidas por monocitos y macrófagos, representan mecanismos importantes de la respuesta del hospedero frente a $C$. albicans, como se demostró al infectar líneas celulares de macrófagos B10R y B10S, derivadas de cepas congénicas de ratón al $B c g$ / Nramp1. Estas mostraron que macrófagos con el fenotipo de resistencia (B10R) resultaban más efectivas en el control de la infección (68).

En un trabajo realizado con cepas de ratones resistentes (BALB/c) y susceptibles $(\mathrm{CHA} / \mathrm{CaH})$, ambas con la mutación nu/nu, se encontró que los ratones atímicos eran más resistentes a la infección sistémica por Candida que los heterocigóticos nu/+. Alternativamente, la protección observada en estas cepas desnudas podría estar asociada con un incremento cuantitativo en la producción medular de células efectoras con actividad anti-Candida (69).

Estos hallazgos confirman que en la candidiasis sistémica, la severidad de las lesiones es independiente de los linfocitos $T$ y reafirma la hipótesis referente a la independencia del daño tisular causado en cada una de las cepas consanguíneas y a la función efectora de los macrófagos o de sus precursores (69). 


\section{Patrón de citocinas}

Las diferencias en susceptibilidad y resistencia a C. immitis de las cepas murinas consanguíneas, son expresadas y probablemente reguladas a través de la producción preferencial de IFN $\gamma$ o de IL-4. Un análisis de citocinas en el ámbito de su expresión génica (ARNm) y proteica reveló que después de la inoculación con el microorganismo por vía respiratoria, los ratones de la cepa resistente DBA/2 presentaban en el pulmón una respuesta predominante de IFN $\gamma$. Por el contrario, los ratones susceptibles BALB/c producian preferencialmente IL-4. La importancia de esas citocinas como determinantes de enfermedad sistémica se hizo evidente al tratar los ratones con citocinas murinas recombinantes o con anticuerpos neutralizantes anticitocinas. Fue así como el tratamiento de ratones susceptibles $\mathrm{BALB} / \mathrm{c}$ con rIFN $\gamma$ los protegió de la diseminación sistémica mientras que, al tratar los ratones resistentes DBA/2 con anticuerpos neutralizantes anti-IFN $\gamma$, se facilitaba el progreso de la enfermedad (70). También se ha observado una correlación directa entre la susceptibilidad a $C$. immitis y niveles pulmonares incrementados de ARNm para IL-10 e IL-4 en ratones consanguíneos de la cepa susceptible C57BL/6, 14 días después de la infección.

En experimentos con ratones C57BL/6 knock-out (K-O), sin el gen para IL-10 e IL-4, se encontró que los ratones $\mathrm{K}-\mathrm{O}$ sin gen para IL-10 eran resistentes a la infección por $C$. immitis; los ratones $\mathrm{K}-\mathrm{O}$ sin el gen para IL-4 sobrevivieron parcialmente y tuvieron una neumonía menos severa que los ratones susceptibles supervivientes, en los que se encontró un número mayor de unidades formadoras de colonias en pulmones e hígado que en los ratones $\mathrm{K}-\mathrm{O}$ sin el gen para IL-10. Estos hallazgos muestran que niveles altos de IL-10 condicionan la mayor susceptibilidad de los ratones C57BL/6; sin embargo, la IL-4 también afecta adversamente la resistencia. Estos resultados sugieren que los altos niveles de IL-10 e IL-4 no son, simplemente, la consecuencia de una infección severa en un animal susceptible; por el contrario, estas citocinas son parcialmente responsables de la susceptibilidad a la infección (71).
Se ha evaluado también el patrón de citocinas producido por ratones resistentes y susceptibles durante el curso de la infección intraperitoneal por $P$. brasiliensis. Los resultados revelaron que había una temprana producción de IFN $\gamma$ e IL-2 en células totales de ganglio linfático de ratones resistentes, la cual persistía por cierto tiempo. Las citocinas del tipo TH2 (IL-4 e IL-5) empezaban a aparecer a las ocho semanas después de la infección, a diferencia de lo observado en los ratones susceptibles, que en la fase temprana de la infección producían bajos niveles de IFN $\gamma$ y altos niveles de IL-5 e IL-10 (72).

En un modelo murino de infección con $C$. albicans, se analizó la respuesta del hospedero de acuerdo con la expresión de algunas citocinas de importancia tales como IFN $\gamma$, TNF $\alpha$ e IL-6, las que pueden ser producidas independientemente de los linfocitos T. Se demostró que no mediaban la resistencia de los ratones atímicos. Es posible, entonces, que las células efectoras encargadas del aumento de la resistencia en los ratones desnudos respondan a señales de activación proporcionadas por citocinas diferentes a las cuantificadas en el experimento (69).

En la histoplasmosis, los estudios realizados con el objeto de estimar el papel potencial del IFN $\gamma$ en la respuesta de ratones $\mathrm{A} / \mathrm{J}$ y $\mathrm{C} 57 \mathrm{BL} / 6$, resistentes y susceptibles, respectivamente, encontraron que el IFN $\gamma$ producido por células esplénicas alcanzaba altas concentraciones en ambas cepas, siendo mayores en los ratones $\mathrm{A} /$ J. Estos ratones sobrevivían todos después de 30 días postinfección intravenosa con $H$. capsulatum, a diferencia de $60 \%$ de los animales de la cepa C57BL/6. Igualmente, los ratones A/J fueron más eficientes para eliminar el hongo del bazo. Se confirmó la importancia del IFN $\gamma$ en la respuesta al tratar ambas cepas con anticuerpos anti-IFN $\gamma$. Aunque la disminución en la producción de IFN $\gamma$ es sólo uno de los factores involucrados, su ausencia o su producción reducida no son suficientes para determinar la susceptibilidad a la histoplasmosis (47).

Como se observa en el cuadro 3 , el patrón de citocinas está determinado por la constitución genética de los individuos, así que sería de gran 
importancia hacer este tipo de estudio en humanos con micosis sistémicas y determinar si, a pesar de la heterogeneidad en su constitución, se encuentran polimorfismos en genes para las citocinas que pudieran determinar el tipo de respuesta inmune en las micosis citadas, como ha sido establecido ya para otras entidades $(10,14)$.

\section{Importancia de los factores del complemento}

La presencia del componente C5 del complemento no parece jugar un papel determinante en el resultado de la infección por $P$. brasiliensis, ya que las tres cepas más resistentes (A/Sn, A/J y $\mathrm{DBA} / 2$ ) son deficientes en C5 (38).

En estudios con $C$. albicans, realizados para observar patrones de resistencia/susceptibilidad en ocho cepas consanguíneas, A/J, AKR, BALB/ c, C57BL/6, CBA/CaH, DBA/1, DBA/2 y SJL, se compararon tres formas diferentes de medir la infección, a saber, daño tisular, recuento de colonias y mortalidad. Sólo los ratones de dos cepas, AKR y CBA/CaH presentaban lesiones severas, las otras cepas, lesiones leves. La susceptibilidad se evaluó por la mortalidad, la cual ocurrió en animales de las cepas $\mathrm{CBA} / \mathrm{CaH}, \mathrm{A} / \mathrm{J}$ y $\mathrm{DBA} / 2$, careciendo las dos últimas del componente $\mathrm{C} 5$ del complemento con leve daño tisular y mayor número de UFC. Los recuentos de colonias en tejido cerebral variaron entre cepa y cepa, sin correlación entre la extensión y la severidad de la destrucción tisular. Sin embargo, las cepas que carecían de C5 tuvieron una carga micótica mayor en el tejido cerebral que los ratones con niveles normales de este factor (52). No obstante, la presencia del alelo nulo del gen $\mathrm{HC}$ no fue un determinante suficientemente potente para que se desarrollaran las lesiones más graves, ya que la cepa AKXL5, deficiente en C5, desarrolló lesiones iguales a las de AKR con severidad intermedia (53). Por tanto, estos resultados no son concluyentes para definir si el gen $\mathrm{Hc}$ determina la resistencia o susceptibilidad a C. albicans.

Al infectar cepas consanguíneas de ratón con Cryptococcus neoformans, los resultados dividieron los animales en dos grupos de acuerdo con los tiempos de supervivencia: susceptibles, si sólo sobrevivían 4 días o menos, y resistentes, si lo hacían por más de 13 días. Esta diferencia en la susceptibilidad se correlacionó con el fenotipo $C^{\prime}$ (presencia o ausencia del componente C5 del complemento), rasgo que es hereditario, estable y que aparece bajo el control de un solo gen. El análisis de segregación de las progenies de F2 y de los retrocruzamientos mostraron que la susceptibilidad y la resistencia se cosegregaban con la ausencia y la presencia del fenotipo C' hemolítico, respectivamente (48).

En el caso de $B$. dermatitidis, también se ha demostrado que las deficiencias en los factores del complemento no alcanzan a explicar las diferencias en la respuesta inmune de cepas murinas resistentes y susceptibles (41).

\section{Conclusiones y perspectivas}

De acuerdo con los hallazgos aquí revisados, parece evidente que, en las micosis sistémicas, la constitución genética del hospedero influye sobre los diferentes componentes de la repuesta inmune.

En cada una de las micosis consideradas, los experimentos iniciales consistieron en infectar con el respectivo agente causal, diferentes cepas consanguíneas de ratones. Se encontró así que la distribución del patrón de rasgos de resistencia/ susceptibilidad están bien definidos y son propios

Cuadro 3. Patrón de citocinas y su relación con la infección durante la fase temprana.

\begin{tabular}{lccc}
\hline Agente micótico & Cepa de ratón & Citocina & Referencia \\
\hline C. immitis & Resistente (DBA/2) & IFN $\gamma$ & 68 \\
P. brasiliensis & Susceptible (BALB/c) & IL-4 & 70 \\
H. capsulatum & Resistente (A/Sn) & IFN $\gamma$, IL-2 & 47 \\
\hline
\end{tabular}


para cada una de las cepas estudiadas. Los experimentos posteriores tuvieron como objetivo infectar con estos microorganismos ratones de cepas consanguíneas consideradas como totalmente resistentes o susceptibles a ellos, con el fin de evaluar varios aspectos de la respuesta inmune.

En relación con el $\mathrm{CMH}$, las cepas más resistentes y las más susceptibles para cada micosis demostraron poseer el mismo alelo $\mathrm{CMH}$, por lo que las diferencias no pueden ser explicadas en función de los correspondientes genes (32,38-41). Cuando se compararon las micosis sistémicas causadas por $C$. albicans y $C$. neoformans, los patrones $\mathrm{CMH}$ se invirtieron con relación a la resistencia y la susceptibilidad. Esto podría explicarse, al menos parcialmente, porque estos dos microorganismos se comportan más como gérmenes oportunistas que como patógenos verdaderos y los neutrófilos desempeñan un papel importante en la candidiasis (53) y el factor C5 del complemento en la criptococosis (48).

En las micosis mencionadas, los estudios revelaron que la respuesta inmune mediada por células era fundamental para el control de las enfermedades por ellos causadas. En modelos murinos de coccidioidomicosis (44) y paracoccidioidomicosis $(57,64)$, se observó que la función de las células T era indispensable para el control de la infección, a diferencia del modelo de candidiasis, en el cual la severidad de las lesiones era independiente de tales células. Por el contrario, como fuera ya anotado, en esta micosis la función defensora crucial parece ser ejercida por el PMN (53).

En paracoccidioidomicosis, los estudios hechos para evaluar los papeles que desempeñan los PMN (63), los linfocitos T $(57,64)$ y los macrófagos $(51,58,60-62)$ han revelado que cada una de estas células juega un papel importante en la fisiopatogenia de la entidad.

En cuanto al patrón de citocinas predominantes en cada micosis, la coccidioidomicosis y la paracoccidioiodomicosis han sido los modelos más estudiados. En el primero, se ha observado cómo los ratones resistentes producen elevadas concentraciones de IFN $\gamma$ y en ratones susceptibles predomina la producción de IL-10 e IL-4, citocinas que, además de ser consecuencia de la infección, son parcialmente responsables de la susceptibilidad a ésta $(70,71)$. En la infección por P. brasiliensis se ha encontrado que los ratones resistentes producen IFN $\gamma$ e IL-2 en la fase temprana de la infección y, más tardíamente, IL4 e IL-5. Esto contrasta con el comportamiento de los ratones susceptibles, los cuales produjeron, inicialmente, concentraciones altas de IL-10 e IL5 y bajas de IFN $\gamma(72)$.

En el modelo murino de histoplasmosis se anotó que el IFN $\gamma$ era importante para el control de la infección, tanto en cepas resistentes como susceptibles. Sin embargo, las cepas resistentes producían más IFN $\gamma(47)$.

En las micosis citadas, los estudios que se han realizado sugieren que el supuesto gen que confiere resistencia es de tipo autosómico y dominante el fenotipo de resistencia. Las cepas murinas congénicas infectadas con $\mathrm{H}$. capsulatum (38) y $P$. brasiliensis (47), presentan una distribucion del rasgo de resistencia similar al observado con otros patógenos intracelulares no relacionados, antigénica ni taxonómicamente, como Salmonella typhimurium, Leishmania donovani $(22,73)$ y determinadas especies de Mycobacterium como Mycobacterium bovis (18) y Mycobacterium lepraemurium (74). En el ratón, la resistencia o susceptibilidad natural a la infección por estos parásitos está controlada por el gen Nramp1. En los macrófagos, este gen controla la replicación y supervivencia de estos parásitos en la fase temprana de la infección $(18,19,21)$. Sería importante determinar si también Nramp1 influye en la resistencia del hospedero frente a $P$. brasiliensis e $H$. capsulatum.

Sin embargo, en la infecciones por $C$. immitis $(31,43,44)$ y $P$. brasiliensis (51), existen evidencias que señalan cómo el gen que influye en la respuesta inmune no es expresado en la fase temprana de la infección, sino en fases posteriores de la enfermedad, cuando interviene en el desarrollo de la inmunidad adquirida. Además, el tiempo de replicación de una bacteria es muy diferente al de un hongo, de tal forma que la expresión del gen responsable de la respuesta 
podría estar condicionada, en parte, por el tiempo que un determinado microorganismo tarda en multiplicarse en el hospedero, así como del tipo de interacción que se establece en cada caso.

El objetivo de la investigación en este campo, más que centrarse en la localización de un gen responsable de la respuesta defensora del hospedero frente a cada microorganismo, debería comprender estudios simultáneos que permitieran entender la interacción entre los genes ya conocidos y la forma en que operaría tal interacción en el modelo murino.

En general, en las micosis mencionadas aún es necesario precisar ciertos aspectos y complementar los estudios que evalúen cada uno de los componentes de la respuesta inmune. De acuerdo con los resultados de los modelos murinos estudiados, se podrían definir los aspectos susceptibles de intervención y que tuvieran mayor importancia como reflejo para el modelo humano. De esta forma, sería posible entender la fisiopatogenia de estas enfermedades y con el conocimiento adquirido, generar mecanismos más efectivos para prevenirlas, diagnosticarlas y tratarlas, especialmente en el momento de su presentación, lo cual adquiere mayor importancia en estos momentos, cuando la incidencia de las micosis se está incrementado día a día.

\section{Referencias}

1. Murphy JW. Mechanisms of natural resistance to human pathogenic fungi. Ann Rev Microbiol 1991;45:50938.

2. Sorensen TI, Nielsen GG, Andersen PK, Teasdale TW. Genetic and environmental influences on premature death in adult adoptees. N Engl J Med 1988;318:72732.

3. Comstock GW. Tuberculosis in twins: a reanalysis of the Prophit survey. Am Rev Respir Dis 1978;117:621-4.

4. McLeod R, Buschman E, Arbuckle DL, Skamene E. Immunogenetics in the analysis of resistance to intracellular pathogens. Curr Opin Immunol 1995;7: 53952.

5. Abel L, Dessein AJ. Genetic epidemiology of infectious diseases in humans: design of population-based studies. Emerg Infect Dis 1998;4:593-603.

6. Bellamy R, Hill AVS. Genetic susceptibility to mycobacteria and other infectious pathogens in humans. Curr Opin Immunol 1998;10:483-7.
7. Hill AVS, Allsopp CEM, Kwiatkowski D, Antey NM, Twumasi P, Rowe PA, et al. Common West African HLA antigens are associated with protection from severe malaria. Nature 1991;352:595-600.

8. Thursz MR, Kwiatkowski D, Allsopp CEM, Greenwood BM, Thomas HC, Hill AVS. Association of an HLA class II allele with clearance of Hepatitis B virus infection in The Gambia. N Engl J Med 1995;332:1065-9.

9. Thursz MR, Thomas HC, Greenwood BM, Hill AVS. Heterozygote advantage for HLA class II type in Hepatitis B virus infection. Nat Genet 1997;17:11-2.

10. Roy S, McGuire W, Mascie-Taylor CGN, Saha B, Hazra SK, Hill AVS, et al. Tumour necrosis factor promoter polymorphism and susceptibility to lepromatous leprosy. J Infect Dis 1997;176:530-2.

11. McGuire W, Hill AVS, Allsopp CEM, Greenwood BM, Kwiatkwoski D. Variation in the TNF- $\alpha$ promoter region associated with susceptibility to cerebral malaria. Nature 1994;371:508-11.

12. Cabrera M, Shaw MA, Sharples C, Williams H, Castes M, Convit J, et al. Polymorphism in the tumour necrosis factor genes associated with mucocutaneous leishmaniasis. J Exp Med 1995;182:1259-64.

13. Nadel S, Newport MJ, Booy R, Levin M. Variation in the tumour necrosis factor- $\alpha$ gene promoter region may be associated with death from meningococcical disease. J Infect Dis 1996;174:878-80.

14. Jouanguy E, Lamhamedi-Cherradi S, Altare F, Fondanèche MC, Tuerlinckx D, Blanche $\mathrm{S}$, et al. Partial interferon- $\gamma$ receptor 1 deficiency in a child with tuberculoid Bacillus Calmette-Guérin infection and a sibling with clinical tuberculosis. J Clin Invest 1997;11: 2658-64.

15. Newport MJ, Huxley CM, Huston S, Hawrylowics CM, Oostra BA, Williamson $\mathbf{R}$, et al. A mutation in the interferon gamma receptor gene and susceptibility to mycobacterial infection. N Engl J Med 1996;335: 1941-9.

16. Wilkinson RJ, Pate $P$, Llewelyn M, Hirsch CS, Pasvol G, Snounou G, et al. Influence of polymorphism in the genes for the interleukin (IL)-1 receptor antagonist and IL-1b on tuberculosis. J Exp Med 1999;189;12:1863-73.

17. Summerfield JA, Sumiya M, Levin M, Turner MW. Associations of mutations in mannosa binding protein gene with childhood infection in consecutive hospital series. Br Med J 1997;314:1229-32.

18. Gros P, Skamene E, Forget A. Genetic control of natural resistance to Mycobacterium bovis (BCG) in mice. J Immunol 1981;127:2417-20.

19. Vidal SM, Malo D, Vogan K, Skamene E, Gros P. Natural resistance to infection with intracellular parasites: Isolation of a candidate for Bcg. Cell 1993;73:46985. 
20. Blackwell JM, Barton CH, White JK, Roach T, Shaw M-A, Whitehead SH, et al. Genetic regulation of leishmanial and mycobacterial infections: the Lsh/lty/Bcg gene story continues. Immunol Letters 1994;43: 99-107.

21. Govoni G, Vidal S, Gauthier S, Skamene E, Malo D, Gros P. The Bcg/lty/Lsh locus: genetic transfer of resistance to infections in C57BL/6J mice transgenic for the Nramp1 ${ }^{\text {Gly169 }}$ allele. Infect Immun 1996;64:2923-9.

22. Skamene E, Gros $P$, Forget A, Kongshavn $P$, Charles C, Taylor B. Genetic regulation of resistance to intracellular pathogens. Nature 1982;297:506-9.

23. Schurr E, Radzioch D, Malo D, Gros P, Skamene E. Molecular genetics of inherited susceptibility to intracellular parasites. Behring Inst Mitt 1991;88:1-12.

24. Cellier M, Govoni G, Vidal S, Kwan T, Groulx N, Liu $\mathbf{J}$, et al. Human natural resistance-associated macrophage protein cDNA cloning, chromosomal mapping, genomic organization, and tissue specific expression. J Exp Med 1994;180:1741-52.

25. Gruenheid S, Pinner E, Desjardins M, Gros P. Natural resistance to infection with intracellular pathogens: the Nramp1 protein is recruited to the membrane of the phagosome. J Exp Med 1997;185:717-30.

26. Cellier M, Shustik C, Dalton W, Rich E, Hu J, Malo D, et al. Expression of the human NRAMP1 gene in professional primary phagocytes: studies in blood cells and in HI-60 promyelocytic leukemia. J Leukoc Biol 1997; 61:96-105.

27. Blackwell J. Structure and function of the natural-resistance-associated macrophage protein (Nramp1), a candidate protein for infectious and autoimmune disease susceptibility. Mol Med Today 1996;2:205-11.

28. Abel L, Sánchez F, Oberti J, Thuc NV, Hoa LV, Lap VD, et al. Susceptibility to leprosy is linked to human NRAMP1 gene. J Infect Dis 1998;177:133-45.

29. Rippon JW. Characteristics of fungi. En: Rippon JW, editor. Medical mycology: the pathogenic fungi and the pathogenic actinomycetes. $3^{\text {rd }}$ ed. Philadelphia: W.B. Saunders; 1988. p.121-53.

30. Pappagianis D. Epidemiology of coccidioidomycosis. En: Stevens DA, editor. Coccidioidomycosis. New York: Plenum Publishing Corp.; 1980. p.63-85.

31. Cox RA. Coccidiodomycosis. En: Cox RA, editor. Immunology of the fungal diseases. Boca Ratón, FL.: CRS Press; 1989. p.165-97.

32. Kirkland TN, Fierer J. Inbred mouse strains differ in resistance to lethal Coccidioides immitis infection. Infect Immun 1983;40:912-6.

33. Greer DL, Restrepo A. La epidemiología de la paracoccidioidomicosis. Bol Of Sanit Panam 1977;83: 428-45.

34. Goldani LZ, Monteiro CMC, Donadi EA, Martinez R, Voltarelli JC. HLA antigens in Brazilian patients with paracoccidioidomycosis. Mycophatologia 1991;114:8991.

35. Lacerda GB, Arce-Gomez B, Queiros-Telles F. Increased frequency of HLA-B40 in patients with paracoccidioidomycosis. J Med Vet Mycol 1988;26: 253-6.

36. Restrepo F, Restrepo M, Restrepo A. Blood groups and HLA antigens in paracoccidioidomycosis. Sabouraudia 1983;21:35-9.

37. Demessias IJT, Reis A, Brneden M, Qeiroz Tellez F, Mauff G. Association of major histocompatibility complex class III complement components $\mathrm{C} 2$, BK, C4 with Brazilian paracoccidoidomycosis. Complement Inflammation 1991;8:5-6.

38. Calich VLG, Singer-Vermes LM, Siqueira AM, Burger E. Susceptibility and resistance of inbred mice to Paracoccidioides brasiliensis. Br J Exp Pathol 1985; 66:585-94.

39. Ashman RB, Papadimitriou JM. Murine candidiasis: pathogenesis and host responses in genetically distinct inbred mice. Immunol Cell Biol 1987;65:163-71.

40. Chick EW, Roberts GD. The varying susceptibility of different genetic strains of laboratory mice to Histoplasma capsulatum. Mycopathol Mycol Appl 1974; 52:251-3.

41. Morozumi PA, Halpern JW, Stevens DA. Susceptibility differences of inbred strains of mice to blastomycosis. Infect Immun 1981;32:160-8.

42. Morozumi PA, Brummer E, Stevens DA. Strain differences in resistance to infection reversed by route of challenge: studies in blastomycosis. Infect Immun $1981 ; 34: 623-5$.

43. Cox R, Kennell W, Boncyk L, Murphy J. Induction and expression of cell-mediated immune responses in inbred mice infected with Coccidioides immitis. Infect Immun 1988;56:13-7.

44. Kirkland TN, Fierer J. Genetic control of resistance to Coccidioides immitis: a single gene that is expressed in spleen cells determines resistance. J Immunol 1985;135: 548-52.

45. Hector RF, Dommer JE, Carrow EW. Immune responses to Candida albicans in genetically distinct mice. Infect Immun 1982;38:1020-8.

46. Marquis G, Montplaisir S, Pelletier M, Mousseau S, Auger P. Strain-dependent differences in susceptibility of mice to experimental candidosis. J Infect Dis 1986; 154:906-9.

47. Wu-Hsieh B. Relatives susceptibilities of inbred mouse strains $\mathrm{C} 57 \mathrm{BL} / 6$ and $\mathrm{A} / \mathrm{J}$ to infection with Histoplasma capsulatum. Infect Immun 1989;57:3788-92.

48. Rhodes JC, Wicker LS, Urba WL. Genetic control of susceptibility to Cryptococcus neoformans in mice. Infect Immun 1980;29:494-9. 
49. Stach J, Gros P, Forget A, Skamene E. Phenotypic expression of genetically-controlled natural resistance to Mycobacterium bovis (BCG). J Immunol 1984;132:888-92.

50. Fierer J, Walls L, Wright F, Kirkland T. Genes influencing resistance to Coccidioides immitis and the interleukin-10 response map to chromosomes 4 and 6 in mice. Infect Immun 1999;67:2916-9.

51. Calich VLG, Burger E, Kashino SS, Fazioli RA, Singer-Vermes LM. The resistance to Paracoccidioides brasiliensis is controlled by a single dominant autosomal gene. Infect Immun 1987;55:1919-23.

52. Ashman RB, Bolitho EM, Papadimitriou JM. Patterns of resistance to Candida albicans in inbred mouse strains. Immunol Cell Biol 1993;71:221-5.

53. Ashman RB, Fulurija A, Papadimitriou JM. Evidence that two independent host genes influence the severity of tissue damage and susceptibility to acute pyelonephritis in murine systemic candidiasis. Microb Pathog 1997;22:187-92.

54. Ashman RB. A gene (Carg1) that regulates tissue resistance to Candida albicans maps to chromosome 14 of the mouse. Microb Pathog 1998;25:333-5.

55. Wu-Hsieh BA. Resistance mechanisms in murine experimental histoplasmosis. Arch Med Res 1993;24:233-8.

56. Beaman L, Pappagianis D, Benjamini E. Significance of $T$ cells in resistance to experimental murine coccidioido-mycosis. Infect Immun 1977;17:580-5.

57. Burger E, Xidieh CF, Sano A, Kashino SS, Vaz CAC, Singer-Vermes LM, et al. Paracoccidioidomycosis in athymic and euthymic mice. Abstracts $8^{\text {th }}$ International Congress of Immunology, Budapest. 1992; Abstr \# W-78:497.

58. Calich VLG, Singer-Vermes LM, Russo M, Vaz CAC, Burger E. Immunogenetics in paracoccidioidomycosis. En: Lacaz CS, Del Negro G, Restrepo A, Franco $\mathrm{M}$, editors. Paracoccidioidomycosis. Boca Ratón, FL: CRC Press; 1994. p.151-73.

59. Cafalli-Favatti C, Russo M, Singer-Vermes LM, Burger E, Calich VLG. Expression of class II MHC antigens by adherent cells in experimental paracoccidioidomycosis. Abstracts $8^{\text {th }}$ International Congress of Immunology, Budapest. 1992; Abstr \# W-78:497.

60. Bretaña A, Goihman-Yahr M, Tapia FJ, Istúriz G, Viloria $\mathrm{N}$, Carrasquero $\mathrm{M}$, et al. Comparative ultraestructure and immunolabeling of $\mathrm{MHC}$-II antigens of alveolar macrophages obtained from patients with paracoccidioidomycosis and other lung diseases. $J$ Leukoc Biol 1995;57:101-9.

61. Bocca AL, Silva MF, Silva CL, Cunha FQ, Figuereido F. Macrophage expression of class II Major Histo-compatibility Complex gene products in Paracoc-cidioides brasiliensis infected mice. Am J Trop Med Hyg 1999;61:280-7.
62. Cano LE, Singer-Vermes LM, Vaz CAC, Russo M, Calich VLG. Pulmonary paracoccidioidomycosis in resistant and susceptible mice: relationship among progression of infection bronchoalveolar cell activation, cellular immune response, and specific isotype patterns. Infect Immun 1995;63:1777-83.

63. Meloni-Bruneri LH, Campa A, Abdalla DSP, Calich VLG, Lenzi HL, Burger E. Neutrophil oxidative metabolism and killing of $P$. brasiliensis after air pouch infection of susceptible and resistance mice. J Leukoc Biol 1996;59: 526-33.

64. Gesztesi JL, Dias MA, de Souza AR, de Almeida SR, Lopes JD, Mariano M. Subcutaneus infection of mice with Paracoccidioides brasiliensis induces a peculiar pattern of inflammatory and immune responses. Mycopathologia 1999;145:7-14.

65. Xidieh CF, Lenzi HL, Calich VLG, Burger E. Influence of the genetic background on the pattern of lesions developed by resistant and susceptible mice infected with Paracoccidioides brasiliensis. Med Microbiol Immunol 1999;188:41-9.

66. Ashman RB. Murine candidiasis: cell-mediated immune responses correlate directly with susceptibility and resistance to infection. Immunol Cell Biol 1990;68:15-20.

67. Ashman RB. Genetic resistance to Candida albicans infection is conferred by cells derived from the bone marrow. J Inf Dis 1992;166:947-8.

68. Puliti M, Radzioch D, Mazzolla R, Barluzzi R, Bistoni F, Blasi E. Influence of the Bcg locus on macrophage response to the dimorphic fungus Candida albicans. Infect Immun 1995;63:4170-3.

69. Fulurija A, Ashman RB, Papadimitriou JMI. Increased tissue resistance in the nude mouse against Candida albicans without altering straint-dependent differences in susceptibility. J Med Vet Mycol 1997;35:197-203.

70. Magee M, Cox R. Roles of interferon and interleukin4 in genetically determinated resistance to Coccidioides immitis. Infect Immun 1995;63:3514-9.

71. Fierer J, Walls L, Eckmann L, Yamamoto T, Kirkland T. Importance of interleukin-10 in genetic susceptibility of mice to Coccidioides immitis. Infect Immun 1998;66: 4397-02.

72. Calich VLG, Kashino SS. Cytokines produced by susceptible and resistance mice in the course of Paracoccidioides brasiliensis infection. Braz J Med Biol Res 1998;31:615-23.

73. O'Brien A, Rosenstreich D, Taylor B. Control of natural resistance to Salmonella typhimurium and Leishmania donovani in mice by closely linked but distinct genetic loci. Nature 1980;287:440-5.

74. Brown IN, Glynn AA, Plant J. Inbred mouse strain resistance to Mycobacterium lepraemurium follows the Ity/Lsh pattern. Immunol 